\title{
INFLUÊNCIA DE DOSES CRESCENTES DE VINHAÇA, COM E SEM COMPLEMENTAÇÃO DE POTÁSSIO, NA QUALIDADE TECNOLÓGICA, PRODUTIVIDADE E MATURAÇÃO, EM SOQUEIRA DE CANA-DE-AÇÚCAR (Saccharum spp)
}

\author{
NAZARENO TRAVAGLINI JUNIOR \\ Engenheiro Agrônomo
}

Orientador: Prof. Dr. MARCO ANTONIO AZEREDO CESAR

Dissertação apresentada à Escola Superior de Agricultura "Luiz de Queiroz", da Universidade de São Paulo, para obtenção do título de Mestre em Ciências, Área de Concentração: Ciência e Tecnologia de Alimentos

PIRACICABA

Estado de São Paulo - Brasil

novembro - 1999 


\section{ERRATA:}

*Página iil, em CNPq, leia-se CAPES

*Página 25 , em KCl, leia-se $\mathrm{K}_{2} \mathrm{O}$

*Página 27, incluir:

"3.8.6 $\mathrm{K}^{+}$em mg $\mathrm{L}^{-1}$, medida em fotômetro de chama, utilizando de comparação com curva padrão, segundo metodologia utilizada e indicada pelo Departamento de Ciências Exatas da ESALQ-USP." *Página 28, incluir:

$3.9 .7 \mathrm{~K}_{2} \mathrm{O}$ no caldo, obtido pela conversão de $\mathrm{K}^{+}$para $\mathrm{K}_{2} \mathrm{O}$, pela expressão:

$K_{2} O\left(m g \cdot L^{-1}\right)=L * 1,205$,

Sendo $L=$ leitura obtida em fotômetro.

"Páginas $31,33,35,37,39,41,43$ e 45 , excluir: "para o mês de outubro", 
Dados Internacionais de Catalogação na Publicação (CIP) DIVISÃO DE BIBLIOTECA E DOCUMENTAÇÃO - Campus "Luiz de Queiroz"/USP

\author{
Travaglini, Nazareno Jr. \\ Influência de doses crescentes de vinhaça, com e sem complementação de \\ potássio, na qualidade tecnológica, produtividade e maturação, em \\ soqueira de cana-de-açúcar (saccharum spp) / Nazareno Travaglini Junior. - - \\ Piracicaba, 1999. 50 p. \\ 1999. \\ Dissertação (mestrado) - - Escola Superior de Agricultura Luiz de Queiroz, \\ Bibliografia.
}

1. Vinhaça 2. Cana-de-açúcar 3. Potássio 4. Resíduo indústria sucroalcooleira 5 . Adubo orgânico. Título

"Permitida a cópia total ou parcial deste documento, desde que citada a fonte - O Autor" 
À minha mulher, Denise e a meus filhos, Mateus e Lucas 


\section{AGRADECIMENTOS}

A Deus, pela vida, saúde e possibilidade de realização deste trabalho, e a todos os que de alguma forma ou de outra contribuiram, notadamente :

À Escola Superior de Agricultura "Luiz de Queiróz" / USP, que generosamente abriu suas portas a meu ingresso e permanência neste curso, assim como ao Departamento de Agroindústria, Alimentos e Nutrição da Escola Superior de Agricultura "Luiz de Queiróz" da Universidade de São Paulo;

Ao Prof. Dr. Marco Antonio Azeredo Cesar, pelo acolhimento, oportunidade e orientação no projeto e execução desse curso e dissertação;

No apoio à estatística, à Profa. Dra . Sônia de Stefano Piedade

Na parte laboratorial, ao Sylvino Torrezan e a Rosemary L.S.Mandro;

Na área de informática, ao Rubens Cesar Pereira;

No campo agrícola, ao Benedito Araújo;

No transporte da cana-de-açúcar, ao Eduardo Giovani;

Ao companheirismo dos $\mathrm{Eng}^{\circ} \mathrm{s}$. Agrônomos Ariovaldo Faustino Soares da Silva, Leandro Cesar Bizelli ;

Ao Prof. Dr. Jorge Horii e ao CNPq, pelo auxílio concedido na forma de Bolsa de Estudos. 


\section{SUMÁRIO}

Página

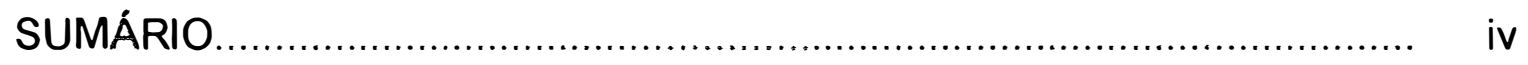

LISTA DE FIGURAS ............................................................. vii

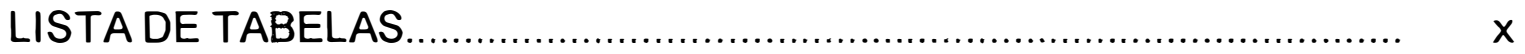

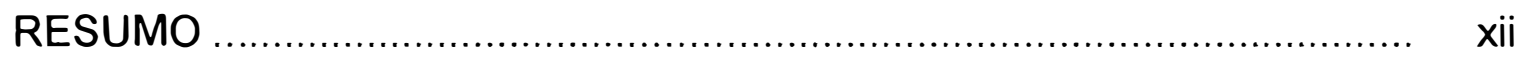

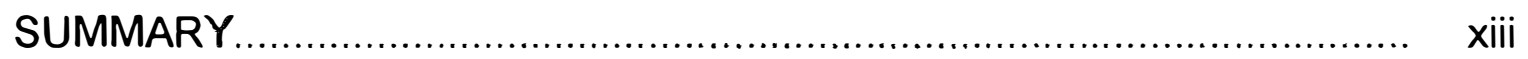

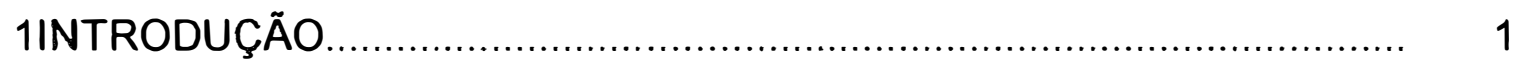

2 REVISÃO DE LITERATURA ...................................................... 3

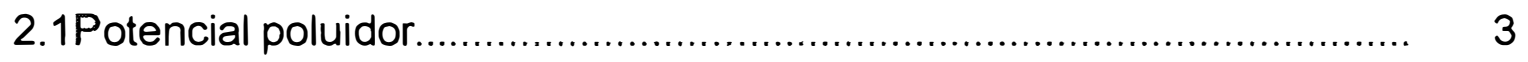

2.2 Origem e composição da vinhaça................................................... 3

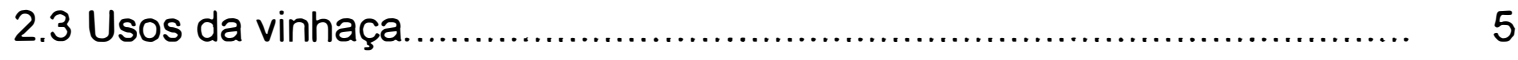

2.4 Valor fertilizante da vinhaça....................................................... 6

2.5 Efeito da vinhaça nas propriedades do solo..................................... 7

2.6 Uso da vinhaça na cultura canavieira................................................ 9

2.7 Efeitos do potássio no metabolismo da cana-de-açúcar..................... 10

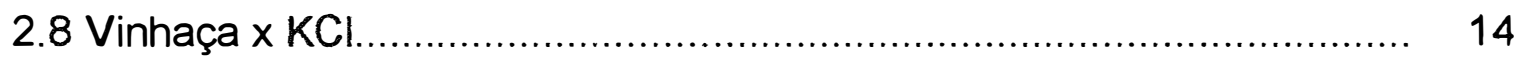

2.9 Influência do uso da vinhaça na produtividade da cana-de-açúcar....... 14 
2.10 Efeitos do uso da vinhaça na qualidade tecnológica da cana-deaçúcar..

3 MATERIAL E MÉTODOS.

3.1 Localização do experimento.

3.2 Clima.

3.3 Cana-de-açúcar.

3.4 Composição da vinhaça.

3.5 Nivel de fertilidade do solo.

3.6 Adubação mineral recomendada.

3.7 Instalação do experimento.

3.8 Amostragem e preparo para análise laboratorial.

3.9 Cálculos com os parâmetros obtidos.

3.10 Cálculos de parâmetros agronômicos.

4 RESULTADOS E DISCUSSÃO.

4. 1 Brix da cana.

4.2 Pol da cana.

4.3 Pureza.

4.4 Açúcares redutores.

4.5 Fibra e umidade na cana.

4.6 Potássio e cinzas.

4.7 Açúcar teórico recuperável.

4.8 Produtividade agrícola. 
$4.10 \mathrm{~K}_{2} \mathrm{O} \times$ cinzas

52

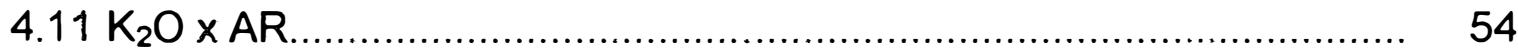

$4.12 \mathrm{~K}_{2} \mathrm{O} \times$ desponte e produtividade de colmos.................................... 55

4.13 Fibra x Pureza x Umidade .............................................................. 56

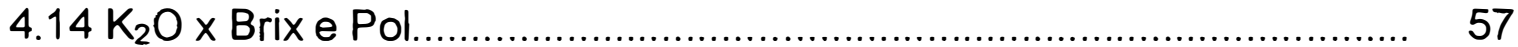

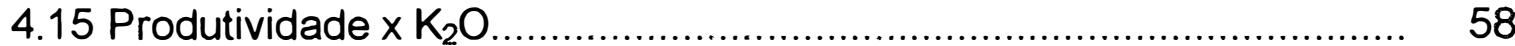

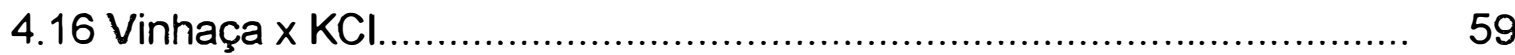

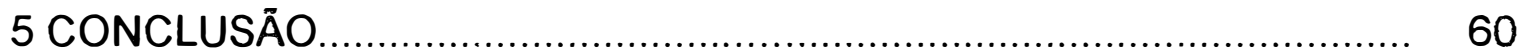

6 APÊNDICE

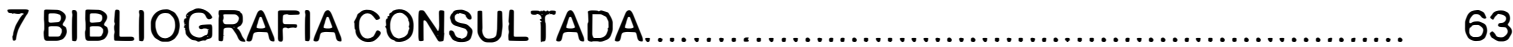




\section{LISTA DE FIGURAS}

Página

1Precipitação e evaporação, em mm, para a região do

experimento

2 Comparação das médias de Brix da cana, para o mês de outubro, apresentando as linhas de tendência e suas equações ajustada

3 Comparação das médias de Pol da cana, para o mês de outubro, apresentando as linhas de tendência e suas equações ajustadas.

4 Comparação das médias de Pureza \% cana, para o mês de outubro, apresentando as linhas de tendência e suas equações ajustadas

5 Comparação das médias de Açúcares Resdutores \% cana, para o mês de outubro, apresentando as linhas de tendência e suas equações ajustadas.

6 Comparação das médias de Fibra \% cana, para o mês de outubro, apresentando as linhas de tendência e suas equações ajustadas

7 Comparação das médias de $\mathrm{K}_{2} \mathrm{O}$ no caldo, para o mês de outubro, apresentando as linhas de tendência e suas equações ajustadas 
8 Comparação das médias de Cinzas \% no caldo, para o mês de outubro, apresentando as linhas de tendência e suas equações ajustadas.

9 Comparação das médias de ATR (kg/t cana), para o mês de outubro, apresentando as linhas de tendência $e$ suas equações ajustadas.

10 Comparação das médias de massa despontada, para o mês de outubro, apresentando as linhas de tendência e suas equações ajustadas.

11 Comparação das médias de número de colmos.ha ${ }^{-1}$, para o mês de outubro, apresentando as linhas de tendência e suas equações ajustadas.

12 Comparação das médias de massa de cana-de-açúcar.ha ${ }^{-1}$, para o mês de outubro, apresentando as linhas de tendência e suas equações ajustadas.

13 Comparação das médias de massa de cana-de-açúcar industrializável.ha ${ }^{-1}$, para o mês de outubro, apresentando as linhas de tendência e suas equações ajustadas.

14 Comparação das médias de produtividade de açúcar, para o mês de outubro, apresentando as linhas de tendência e suas equações ajustadas.

15 Comparação dos teores de $\mathrm{K}_{2} \mathrm{O}$ e cinzas no caldo, em referência à testemunha absoluta (T1). 
16 Comparação dos teores de $\mathrm{K}_{2} \mathrm{O}$ no caldo e Açúcares Redutores na cana, em referência à testemunha absoluta (T1)

17 Comparação dos teores de $\mathrm{K}_{2} \mathrm{O}$ no caldo, desponte e produtividade de colmos, em referência à testemunha absoluta (T1)

18 Comparação dos teores Fibra, Pureza e Umidade \% cana em referência à testemunha absoluta (T1)

19 Comparação dos teores $\mathrm{K}_{2} \mathrm{O}$ no caldo, Brix e Pol da cana em referência à testemunha absoluta (T1)

20 Comparação dos teores $\mathrm{K}_{2} \mathrm{O}$ no caldo, produtividade de cana, cana despontada e de açúcar, em referência à testemunha absoluta (T1)........ 


\section{LISTA DE TABELAS}

Página

1 Diferentes potenciais poluidores de vinhaça de diferentes origens......... 3

2 Composição da vinhaça de várias procedências por diversos autores.... 4

3 Valor fertilizante da vinhaça em equivalência ao adubo comercial........... 6

4 Teores de K no solo, no caldo e nas cinzas....................................... 10

5 Produtividade de colmos de cana-de-açúcar e de Pol, em t.ha-1 ${ }^{-1}$ em solo irrigado com vinhaça e não irrigado, para diferentes variedades

6 Resultados de Análises da Vinhaça utilizada no experimento.

7 Resultados de Análise de Solo (TE) da área do experimento.

8 Recomendação de adubação potássica ( em kg K ${ }_{2} \mathrm{O}$.ha- ${ }^{-1}$ ), em função da classe de fertilidade do solo e da relação w. $\mathrm{t}^{-1}$ ( preço t cana.preço kg nutriente ${ }^{-1}$ ).

9 Quantidades de $\mathrm{K}_{2} \mathrm{O}$ na vinhaça aplicada no experimento 
10 Comparação das médias para Brix da cana, para o mês de outubro.... 31

11 Comparação das médias para Pol da cana, para o mês de outubro......

12 Comparação das médias para Pureza \% cana, para o mês de outubro.

35

13 Comparação das médias para açúcares redutores, para o mês de outubro.

14 Comparação das médias para Umidade \% cana, para o mês de outubro.

15 Comparação das médias para Fibra \% cana, para o mês de outubro....

16 Comparação das médias para $\mathrm{K}_{2} \mathrm{O}\left(\mathrm{mg} \cdot \mathrm{L}^{-1}\right)$ no caldo da cana, para o mês de outubro.

17 Comparação das médias para Cinzas \% no caldo, para o mês de outubro.

18 Comparação das médias para Açúcar Teórico Recuperável, para o mês de outubro.

19 Desponte e a diferença entre tratamentos complementados e não com $\mathrm{KCl}$.

20: Produtividade de açúcar $\left(\mathrm{kg} \cdot \mathrm{ha}^{-1}\right)$ 


\title{
INFLUÊNCIA DE DOSES CRESCENTES DE VINHAÇA, COM E SEM COMPLEMENTAÇÃO DE POTÁSSIO, NA QUALIDADE TECNOLÓGICA, PRODUTIVIDADE E MATURAÇÃO, EM SOQUEIRA DE CANA-DE-AÇÚCAR (Saccharum spp)
}

\author{
Autor: Nazareno Travaglini Junior \\ Orientador: Prof.Dr. Marco Antonio Azeredo Cesar
}

\section{RESUMO}

Em segunda soqueira de cana-de-açúcar, variedade RB78-5148, foram aplicadas doses de 100, 200, 300 e $400 \mathrm{~m}^{3}$. ha-1 de vinhaça diluida, com e sem complementação com KCl, sendo as respostas tecnológicas comparadas com a adubação mineral recomendada e com a fertilidade atual de um solo TE. Os dados obtidos permitiram uma avaliação dos efeitos de doses crescentes de vinhaça na maturação, produtividade agrícola e qualidade tecnológica de cana dessa variedade, assim como uma comparação com o uso do potássio na forma mineral. Concluiu-se que a complementação com $\mathrm{KCl}$ não colabora com o recuperação de açúcar.ha-1 ${ }^{-1}$, além de aumentar o teor de $\mathrm{K}_{2} \mathrm{O}$ e cinzas no caldo; tanto o ATR.ha ${ }^{-1}$ como a produtividade agrícola elevam-se com o aumento das doses de vinhaça; a dose máxima de vinhaça (400 $\mathrm{m}^{3}$.ha ${ }^{-1}$ ) empregada, não foi suficiente para atingir a mesma produtividade de açúcar e massa de cana.ha ${ }^{-1}$ que a adubação NPK recomendada, mas aumentou significativamente os teores de potássio e cinzas no caldo. 


\title{
INFLUENCE OF GROWING DOSES OF VINASSE, WITH AND WITHOUT COMPLEMENTATION OF POTASSIUM, IN THE TECHNOLOGICAL QUALITY, PRODUCTIVITY AND MATURATION, IN ROOTSTOCK OF SUGARCANE (Saccharum spp.)
}

\author{
Author: Nazareno Travaglini Júnior \\ Adviser: Prof. Dr. Marco Antonio Azeredo Cesar
}

\section{SUMMARY}

In the second rootstock of sugar-cane, variety RB78-5148, were applied doses of $100,200,300$ and, $400 \mathrm{~m}^{3}$.ha-1 of diluted vinasse, with and, without complementation with $\mathrm{KCl}$, being the technological answers compared with the recommended chemical fertilization and, with the current fertility of a TE soil. The obtained data allowed an evaluation of the effects of growing doses of vinasse in the maturation, agricultural productivity and technological quality of that cane variety, as well as a comparison with the use of the potassium in the mineral form. It was concluded that the complementation with $\mathrm{KCl}$ doesn't collaborate with the sugar.ha ${ }^{-1}$ recovery, what's more, it increases the content of $\mathrm{K}_{2} \mathrm{O}$ and ashes in the broth; the ATR.ha ${ }^{-1}$ rises as the agricultural productivity with the increase of the vinasse doses; the maximum dose of vinasse $\left(400 \mathrm{~m}^{3}\right.$. ha $\left.{ }^{-1}\right)$ applied was not enough to reach the same productivity of sugar and cane mass.ha- ${ }^{-1}$ as the recommended NPK fertilization, but it increased significantly the potassium and, ashes contents in the broth. 


\section{INTRODUÇÃO}

Segundo informações do Agrianual/99, o setor sucroalcooleiro brasileiro, na safra 96/97, produziu 337.338 mil de toneladas de cana, que foram convertidas em 271.336.240 sacas de $50 \mathrm{~kg}$ de açúcar e $14.254 .882 \mathrm{~m}^{3}$ de álcool. Como em média tem-se, aproximadamente, uma produção de 13 litros de vinhaça por litro de álcool produzido, estimando-se daí uma produção total desse resíduo da ordem de 185 bilhões de litros, sem incluir o produzido pela indústria de aguardente.

A vinhaça revela-se como um elemento de alto potencial poluidor, principalmente pelo seu elevado teor de matéria orgânica, implicando em considerável demanda biológica de oxigênio (DBO) , o que sem dúvida é matéria de preocupação quando se pensa no impacto ambiental que a má destinação desse resíduo pode provocar.

Entretanto, a vinhaça (vinhoto ou restilo) tem variadas formas de emprego, destacando como a principal entre elas sua aplicação direta em áreas de cultivo da cana-de-açúcar, quer seja em cana-planta como em canasoca, em substituição parcial ou total da adubação mineral preconizada, conforme já em uso na maioria das destilarias do Estado de São Paulo. Para que haja um emprego racional e eficiente do uso da vinhaça é de fundamental importância o conhecimento dos níveis atuais de fertilidade do solo, assim como da composição da vinhaça, que sofre grande variação de acordo com sua natureza. 
Além de se dar uma destinação adequada a esta forma de resíduo da destilação, o produtor fará uma grande economia na compra do adubo químico, que na sua maior parte é importado, ainda com vantagem na melhoria das condições físico-químicas do solo.

O presente trabalho visa identificar alterações na qualidade tecnológica e produtividade agrícola da cana-de-açúcar pelo uso da vinhaça em cana-soca; assim como estabelecer um paralelo entre adubação potássica mineral $(\mathrm{KCl})$ e o uso da vinhaça.

Os resultados obtidos estão restritos a uma variedade de cana e às condições do experimento. 


\section{REVISÃO DE LITERATURA}

\subsection{Potencial poluidor}

Craveiro(1986) citando fonte da CETESB mostra que a vinhaça tem um poder de poluição ambiental muito grande, sendo este maior ou menor em função de sua origem, como é mostrado na tabela 1:

Tabela 1 Diferentes potenciais poluidores de vinhaça de diferentes origens

\begin{tabular}{|c|c|c|c|}
\hline material de origem & melaço & caldo & misto \\
\hline $\begin{array}{ll}\text { Demanda } & \text { Bioquímica de } \\
\text { Oxigênio } & \left(\mathrm{mg} \mathrm{O}_{2} \cdot \mathrm{L}^{-1}\right)\end{array}$ & 25000 & $6000-16500$ & 19800 \\
\hline $\begin{array}{lc}\text { Demanda } & \text { Química de } \\
\text { Oxigênio } & \left(\mathrm{mg} \mathrm{O}_{2} \cdot \mathrm{L}^{-1}\right)\end{array}$ & 65000 & $15000-33000$ & 45000 \\
\hline Matéria Orgânica $\left(\mathrm{mg} \mathrm{L}^{-1}\right)$ & 63400 & 19500 & 38000 \\
\hline
\end{tabular}

Fonte: CETESB

\subsection{Origem e composição da vinhaça}

Os primeiros trabalhos realizados com vinhaça visando a determinação de sua composição e utilização na agricultura foram conduzidos por Almeida (1952), constatou ser o resíduo uma suspensão de sólidos, rico em substâncias orgânicas e minerais com predominância de potássio, sugerindo poder ser o resíduo tratado como um espetacular fertilizante potássico. 
Silva \& Orlando Fo. (1981) lembram que a composição da vinhaça depende de uma série de fatores, tais como:

a) tipo de matéria-prima empregada no preparo do mosto (melaço, caldo e misto);

b) procedência ou localização da destilaria;

c)época de amostragem;

d)tipo de processo utilizado na destilação;

no que concordam, Almeida (1952), Rodella \& Ferrari (1977) e Orlando Fo. (1983).

Orlando Fo. (1983), apresentou em uma tabela o resultado da avaliação da composição de vinhaças de várias procedências por diversos autores, que é transportada na tabela 2.

Tabela 2 Composição da vinhaça de várias procedências por diversos autores

\begin{tabular}{|c|c|c|c|c|c|c|c|c|c|c|c|c|}
\hline \multirow[t]{2}{*}{ Elemento } & \multicolumn{4}{|c|}{ mosto de melaço } & \multicolumn{4}{|c|}{ mosto misto } & \multicolumn{4}{|c|}{ mosto de caldo } \\
\hline & (1) & (2) & (3) & (4) & (1) & (2) & (3) & (4) & (1) & (2) & (3) & (4) \\
\hline${ }^{*} \mathrm{~N}$ & 0.57 & 0.79 & 0.70 & 0.60 & 0.48 & 0.43 & 0.36 & 0.33 & 0.28 & 0.35 & 0.26 & 0.25 \\
\hline${ }^{*} \mathrm{P} 2 \mathrm{O} 5$ & 0.10 & 0.14 & 0.34 & 0.22 & 0.09 & 0.14 & 0.61 & 0.24 & 0.09 & 0.11 & 0.49 & 0.18 \\
\hline $\mathrm{K} 2 \mathrm{O}$ & 3.95 & 5.50 & 7.59 & 5.08 & 3.34 & 2.61 & 2.59 & 2.18 & 1.29 & 1.15 & 1.72 & 1.94 \\
\hline${ }^{\star} \mathrm{CaO}$ & 1.85 & 2.25 & 2.41 & 2.10 & 1.33 & 1.46 & 0.57 & 0.84 & 0.13 & 0.76 & 0.17 & 0.56 \\
\hline${ }^{\star} \mathrm{MgO}$ & 0.98 & 1.02 & 1.40 & 0.84 & 0.58 & 0.52 & 0.54 & 0.33 & 0.21 & 0.30 & 0.41 & 0.33 \\
\hline *SO4 & & & 1.05 & & & & 1.60 & & & & 2.03 & \\
\hline${ }^{\star}$ M.org. & 37.30 & 56.90 & 54.68 & 47.40 & 28.97 & 45.10 & 31.67 & 19.10 & 22.31 & 34.70 & 25.24 & 15.30 \\
\hline${ }^{\star \star} \mathrm{Fe}$ & & 120 & 67 & 52 & & 130 & 47 & 57 & & 110 & 51 & 45 \\
\hline${ }^{\star \star} \mathrm{Cu}$ & & 9 & 3 & 3 & & 57 & 2 & 4 & & 18 & 1 & 1 \\
\hline$\star \approx n$ & & 3 & 3 & 4 & & 50 & 3 & 4 & & 2 & 2 & 3 \\
\hline${ }^{\star \star \mathrm{Mn}}$ & & 11 & 6 & 7 & & 5 & 6 & 6 & & 10 & 6 & 5 \\
\hline $\mathrm{pH}$ & 4.2 & 4.2 & 4.4 & 4.2 & 4.4 & 3.8 & 4.0 & 3.6 & 3.7 & 3.6 & 3.6 & 3.5 \\
\hline
\end{tabular}

${ }^{*} \mathrm{~kg} \cdot \mathrm{m}^{-3}$ vinhaça ${ }^{\text {** }} \mathrm{mg} \cdot \mathrm{L}^{-1}$

(1) Rodella et al. (1980); (2) Bolsanello \& Vieira (1980)

(3) Vasconcellos \& Oliveira (1981) ; (4) Medeiros ( 1981)

Fonte: Orlando Fo. (1983) 
Coletti (1978) e Rodella et al. (1980) concordam que a composição da vinhaça de mosto misto na safra varia com os constituintes do mosto, que entram em seu preparo, principalmente quanto a quantidade de melaço.

Em trabalho conduzido com material proveniente de destilarias autônomas Rodella et al. (1980), constatou uma significativa constância dos elementos presentes na composição da vinhaça ao longo da safra, provavelmente em função da origem do mosto ser sempre de caldo.

\subsection{Usos da vinhaça}

Orlando Fo. (1983) dá como opções de uso da vinhaça: produção de proteínas unicelulares por fermentação aeróbica; produção de gás metano; concentração a $60^{\circ}$ Brix e posterior emprego na formulação de ração animal; utilização como adubo na lavoura ou queima para produção de fertilizante; utilização agrícola do resíduo "in natura", substituindo total ou parcialmente as adubações minerais, conforme demonstram Glória \& Magro (1976) e Agujaro (1979).

Srur \& Aquarone (1983) realizaram trabalho com adição de resíduo da fermentação glutâmica ("Amiferm") - também altamente poluente - à vinhaça para obtenção de um substrato para crescimento de $\underline{\text { Rhodotorula }}$ gracilis obtendo rendimento máximo de massa seca de mais de $12 \mathrm{~g} \cdot \mathrm{L}^{-1}$ após $80 \mathrm{~h}$ de fermentação, com teor médio, na massa seca, de 51,43 $\mathrm{g}$ de proteína. $100 \mathrm{~g}^{-1}$ de produto. Além da redução da DBO em $42 \%$ e da acidez do efluente.

Segundo Alves (1987) a adição de fosfato de amônio à vinhaça torna-a um meio favorável a um aumento de biomassa de até $100 \%$, e alcança uma redução da DBO de até $76,8 \%$, permitindo redução do poder poluente, rendimento satisfatório de biomassa utilizável na formulação de formulação de ração animal. 
Outra opção de tratamento da vinhaça é sua concentração para posterior uso agrícola, sendo que Germek e Feigl (1987) mostram que ela é viável até atingir $20^{\circ}$ Brix, pois a concentração descreve uma curva assintótica, e a partir de então a redução de volume é pouco significativa

Rocha (1988) apresenta a biodigestão anaeróbica como a solução mais atraente para o tratamento de efluentes, em vista de: abaixamento drástico da $\mathrm{DBO}$, produção de energia na forma de biogás, produção de biofertilizantes, baixa produção de lôdo já estabilizado, menores custos de investimento e operação.

\subsection{Valor fertilizante da vinhaça}

Em base a teores médios da vinhaça Orlando Fo. et al. (1980) propuseram o valor fertilizante da mesma para cada $\mathrm{m}^{3}$ do resíduo, o que é transportado na tabela 3:

Tabela 3 Valor fertilizante da vinhaça em equivalência ao adubo comercial

\begin{tabular}{|l|c|c|c|}
\hline \multicolumn{3}{|c|}{ tipo de vinhaça } & \multicolumn{2}{c|}{$\begin{array}{c}\text { fertilizante } \\
\left.\text { (kg.m } \mathrm{m}^{-3} \text { de vinhaça }\right) \\
\text { superfosfato triplo }\end{array}$} \\
& uréia & \multicolumn{2}{c|}{ cloreto de potássio } \\
\hline mosto de melaço & 1.89 & 0.33 & 9.58 \\
\hline mosto misto & 1.20 & 0.30 & 5.87 \\
\hline mosto de caldo & 0.69 & 0.29 & 2.02 \\
\hline
\end{tabular}

Fonte: Orlando Fo. et al. (1980) 


\subsection{Efeito da vinhaça nas propriedades do solo}

Glória \& Orlando Fo. (1983) conferem o efeito da vinhaça ao solo semelhante ao da aplicação da matéria orgânica, dada a riqueza da mesma nesse elemento, qual seja: elevação do $\mathrm{pH}$ do solo, aumento da disponibilidade de alguns nutrientes, aumento da CTC, melhor retenção de água, aumento de população e da atividade microbiana do solo, sendo este último corroborado com trabalhos de Glória \& Mattiazzo (1976).

Conforme Glória \& Orlando Fo. (1983) e Glória \& Magro (1976) a elevação da CTC (capacidade de troca catiônica) do solo com a aplicação da vinhaça deve-se a seu alto teor de matéria orgânica, que no entanto não tem ação prolongada, devendo por isso ser repetida sua aplicação a cada ano.

Orlando $\mathrm{F}^{\circ}$. (1983) conclui que a aplicação de doses racionais de vinhaça em solo que não apresente drenagem deficiente traz melhorias nas propriedades físicas e químicas do mesmo.

Coleti et al.(1983) avaliaram as variações das propriedades químicas de cinco solos após a aplicação de vinhaça e observaram que as maiores alterações ocorreram até 100 dias após a aplicação, decrescendo a partir de então. Maiores alterações estão relacionadas com menor fertilidade dos solos, quase sempre arenosos. A complementação mineral é dispensável para obtenção de bons rendimentos agrícola.

Orlando Fo. (1983) mostra que a matéria orgânica em estado coloidal na vinhaça, aplicada ao solo complexaria o alumínio do mesmo, provocando a elevação de seu pH.

Orlando Fo. (1983), citando Orlando Fo. et al. (1983) estudando as propriedades químicas de perfis de solo Latossol Roxo (LR) que estavam recebendo vinhaça há diferentes períodos de tempo ( até 20 anos) não verificaram grandes variações de valores de pH, potássio, cálcio e magnésio em relação à testemunha. 
Robaina et al. (1984) mostram que diante de diferentes doses aplicadas de vinhaça, os efeitos na produção de cana foram influenciados tanto pela textura, quanto pela fertilidade do solo, ocorrendo maior resposta em solos com menor teor de argila ( abaixo de 35\%) elou de baixa fertilidade. $E$ ainda, que os benefícios de uma segunda aplicação de vinhaça são maiores do que os verificados na primeira.

Azeredo et al. (1984) em trabalho com cana-soca, mostraram que a característica do solo que melhor se correlacionou com a resposta em produtividade de cana à aplicação de vinhaça foi a soma de bases mais alumínio.

Mattiazzo \& Glória (1985) relatam que a queda inicial no pH dos solos causada pela adição de vinhaça parece ter diferente origem conforme o tipo de solo. Na Areia Quartzosa nota-se que a adição de vinhaça provocou uma sensivel elevação do nível de alumínio trocável do solo, mas também uma elevação na concentração de íons $\mathrm{H}^{+}$. Para o Podzólico e o Latossol praticamente não houve elevação no teor de $\mathrm{Al}^{+3}$ com adição de vinhaça, mas a queda do $\mathrm{pH}$ é devida ao aumento na concentração dos íons $\mathrm{H}^{+}$.

Furlan et al.(1985), cita Leme et al. (1979) que conduziram trabalhos constatando um acréscimo em porosidade total e macroporos do solo, com aumento da dosagem de vinhaça e aumento da condutividade elétrica na região das raízes.

Cambuim \& Cordeiro (1986) em laboratório avaliaram a lixiviação de elementos em função de doses aplicadas de vinhaça em solos arenosos, constatando que o fósforo tem lixiviação inexpressiva, enquanto potássio, cálcio e magnésio lixiviaram quase que em proporção direta às doses de vinhaça aplicada (200 e $400 \mathrm{~m}^{3} \cdot \mathrm{ha}^{-1}$ ). 
Alves et al. (1995) em experimento com emprego de diferentes doses de vinhaça 150, 300 e $600 \mathrm{~m}^{3}$.ha-1 em solo arenoso constataram que não promoveram aumentos no $\mathrm{NO}_{3}{ }^{2-}$ e $\mathrm{NH}_{4}{ }^{+}$do solo ao longo do perfil, mesmo 25 semanas após a aplicação; e que a dose $300 \mathrm{~m}^{3}$.ha-1 de vinhaça aplicada foi suficiente para aumentar a produtividade agrícola, embora a Pol da cana tendesse a diminuir.

\subsection{Uso da vinhaça na cultura canavieira}

Agujaro (1979) em experimento conduzido na Usina Tamoio obteve aumento da ordem de $67 \%$ na produtividade da cana soca de $4^{\circ}$. Corte em função do uso de vinhaça como fertilizante.

Coelho e Azevedo (1986) fazem uma revisão bibliográfica mostrando a viabilidade técnica e econômica do uso da vinhaça na irrigação da cana-de-açúcar.

Penatti et al. (1988) constataram que melhor resposta à aplicação de vinhaça é obtida em solo com teor de argila inferior a $35 \%$, ou seja, solos que apresentam menor fertilidade tem maiores acréscimos na produção de cana.ha-1. Sendo que a dose de $150 \mathrm{~m}^{3} \cdot \mathrm{ha}^{-1}$ de vinhaça parece suprir as necessidades nutricionais da cana, dispensando complementação mineral, e que resposta linearmente significativa, em produtividade, é obtida com a complementação nitrogenada quando doses de até $100 \mathrm{~m}^{3}$.ha $\mathrm{h}^{-1}$ são aplicadas. Constataram ainda que nas doses aplicadas (0,50, 100 e $\left.150 \mathrm{~m}^{3} \cdot \mathrm{ha}^{-1}\right)$ a qualidade da matéria-prima não foi afetada significativamente. 


\subsection{Efeitos do potássio no metabolismo da cana-de-açúcar}

O Potássio é exigido em altas quantidades e altas concentrações pela cana-de-açúcar. Ele participa de muitos processos vitais das plantas, tais como: biossintese de sacarose, taxa de fotossíntese, migração de açúcares das folhas até o colmo, além de síntese de proteínas, de amido e como co-fator de enzimas do metabolismo. Em vista disso ensaios realizados tem levado à indicação de que elevados níveis de $\mathrm{K}^{+}$em cana-de-açúcar provocam aumento na concentração e produção total de sacarose. Plantas deficientes em $\mathrm{K}^{+}$ apresentam baixo nível de sacarose e alto nível de AR (glicose), mesmo teor de clorofila e menor taxa de fotossíntese comparadas com plantas normais (Alexander, 1973).

Glória \& Magro (1976) apresentam teores de K no solo e seus correspondentes percentuais encontrados no caldo, assim como os percentuais de cinzas no caldo, dados na tabela 4:

Tabela 4 Teores de $\mathrm{K}$ no solo, no caldo e nas cinzas

\begin{tabular}{|c|c|c|}
\hline $\begin{array}{c}\text { Kno solo } \\
\left(\mathrm{mg} \cdot \mathrm{dm}^{3}\right)\end{array}$ & K no caldo (\%) & Cinzas no caldo (\%) \\
\hline 71 & 0.45 & 0.72 \\
\hline 79 & 0.48 & 0.76 \\
\hline 88 & 0.49 & 0.75 \\
\hline 98 & 0.60 & 0.91 \\
\hline 105 & 0.55 & 0.83 \\
\hline 112 & 0.60 & 0.90 \\
\hline 130 & 0.54 & 0.82 \\
\hline 142 & 0.54 & 0.83 \\
\hline 147 & 0.68 & 1.02 \\
\hline 159 & 0.65 & 0.99 \\
\hline
\end{tabular}


Silva et al. (1977) em experimento conduzido com aplicação de vinhaça com complementação nitrogenada mostraram que a dosagem máxima de $\mathrm{K}_{2} \mathrm{O}$ adicionada através da vinhaça deve situar-se entre 300 e $350 \mathrm{~kg}$ de $\mathrm{K}_{2} \mathrm{O} \cdot \mathrm{ha}^{-1}$ para não acarretarem diminuições na produtividade de cana.

Altas doses de $\mathrm{K}$ aplicado, em condições de campo, elevam o teor de $\mathrm{N}$ nas folhas, de modo significativo (Zambello, Jr. 1979).

Zambello, Jr. et al. (1980) encontraram resposta linear para os rendimentos em produtividade agrícola e de açúcar, em soqueira, até a dosagem de $180 \mathrm{~kg} \mathrm{~K}_{2} \mathrm{O} \cdot \mathrm{ha}^{-1}$, em solos LVa, PVls e LE, o que não ocorreu em solo LR.

Orlando $F^{\circ}$. (1982) , citando Epstein (1975), lembra que o potássio na planta desempenha papel de ativador enzimático, e que segundo Hartt (1970), na cana-de-açúcar ele é fundamental para assegurar a estrutura celular para fins de assimilação de carbono, bem como síntese e translocação de proteínas, e ainda que Humbert (1963) constatou que plantas deficientes em potássio perdem a turgidez foliar.

Robaina et al. (1984) mostram o efeito de doses de $\mathrm{K}_{2} \mathrm{O}$ através da aplicação sucessiva de vinhaça sobre o aumento de produção de cana, e efeito de doses de $\mathrm{K}_{2} \mathrm{O}$ através da aplicação de vinhaça em função do teor de argila no solo, sobre a porcentagem de aumento da produtividade de cana.

O excesso de potássio acarreta elevação na cinzas \% cana e decréscimo da Pol da cana, o que está vinculado com o potencial genético da variedade. Isso é justificado pelo maior acúmulo de outros componentes orgânicos, tais como amido e ácido aconítico, além do continuado crescimento vegetativo, que é contrário à acumulação de sacarose Parazzi et al. (1984). 
$\mathrm{Na}$ planta o potássio é parte essencial do processo de síntese proteica e na translocação e armazenamento de açúcares. O acúmulo de potássio decresce o potencial osmótico das células, determinando maior "retenção" de água nos tecidos vegetais, conferindo maior resistência à falta de água. Ainda, o potássio é participante da ativação de enzimas, e assim seu nivel na planta determina o crescimento da planta, interferindo não só na massa vegetal como também no acúmulo de açúcares( Glória, 1985).

Com a prática da fertirrigação e o uso de pesados volumes de vinhaça no campo, notou-se uma diminuição da Pol da cana, atribuindo-se o fato à falta de estresse na cultura e o continuado crescimento vegetativo, o que não favoreceria o acúmulo de sacarose. Orlando et al. (1980), Parazzi et al. (1984), Silva et al.(1977) e Glória \& Magro (1976) citados por Gloria (1985), constaram que o emprego de doses crescentes de potássio proporcionaram decréscimo na Pol da cana, acompanhado pelo aumento de cinzas\% cana; o que não foi confirmado em trabalho de Orlando $F^{\circ}$. et al. (1980), também citados por Glória (1985), sendo que os dois últimos acrescentam que o efeito do potássio na Pol da cana está na dependência varietal da cana, sendo observado que variedades SP mostraram acréscimo na Pol da cana.

Nunes Jr.(1987) mostra que em local de alta deposição de vinhaça (área de sacrifício) a produtividade de colmos é favorecida em prejuizo da maturação. Baixo teor de sacarose pode ser explicado pela excessiva absorção de $\mathrm{K}^{+}$, mostrado pelos altos teores de cinzas no caldo, o que é atribuido a maior quantidade de $\mathrm{K}^{+}$e matéria orgânica no solo. Esse efeito tende a ser minimizado ao longo dos cortes, sendo verificado que variedades comportamse diferentemente.

Avaliando os efeitos de doses de vinhaça na produtividade, Ferreira \& Monteiro (1987) constataram aumento até a dose de $308 \mathrm{~kg}$ de $\mathrm{K}_{2} \mathrm{O}$. $\mathrm{ha}^{-1}$ para a produção de açúcar e de $468 \mathrm{~kg} \mathrm{~K}{ }_{2} \mathrm{O}$. ha-1 para produção de canade-açúcar. 
Glória (1985) relata que o potássio está estreitamente ligado aos processos de assimilação de $\mathrm{CO}_{2}$ e nitrogênio pela planta, favorecendo a formação de proteinas e a translocação e armazenamento de açúcares. A carência de potássio reflete numa menor taxa de crescimento e para a cana-deaçúcar esses reflexos não são apenas no sentido da diminuição da massa produzida como também devido à menor ação fotossintética e menor acumulação de açúcares. Ao contrário o excesso de potássio acarreta elevação na cinzas \% cana e decréscimo da Pol da cana, o que está vinculado com o potencial genético da variedade. Isso é justificado pelo maior acúmulo de outros componentes orgânicos, tais como amido e ácido aconítico, além do continuado crescimento vegetativo, que é contrário à acumulação de sacarose.

Peixoto \& Coelho (1981) conduzindo experimento com diferentes doses de aplicação, por aspersão, de vinhaça diluida $(0,150,300,450,600,750$ e $900 \mathrm{~m}^{3}$.ha-1, diluida mantendo a relação de $1 \mathrm{~kg} \mathrm{~K} \mathrm{~K}_{2} \mathrm{O} \cdot \mathrm{m}^{-3}$ de vinhaça), com e sem complementação mineral, em cana planta, constataram que todos os tratamentos chegaram à maturação no décimo segundo mês da instalação do experimento, embora o valor da Pol da cana na colheita tenha apresentado-se menor do que ao da testemunha, enquanto que o AR foi sempre menor para os tratamentos irrigados com vinhaça, em função do maior desenvolvimento vegetativo. A dose de $150 \mathrm{~m}^{3}$.ha ${ }^{-1}$ substituiu totalmente a adubação mineral.

$\mathrm{O} \mathrm{K}^{+}$participa direta ou indiretamente de inúmeros processos bioquímicos envolvidos com o metabolismo de carboidratos, como a fotossintese e respiração, sendo ativador de um grande número de enzimas encontradas nas células vegetais, principalmente dos grupos das sintetases, oxidoredutases, desidrogenases e quinases, estando estreitamente relacionado com processos de assimilação de $\mathrm{CO}_{2}$ e de nitrogênio, favorecendo a formação de compostos nitrogenados de alto peso molecular, como as preteínas, e a síntese, translocação e armazenamento de açúcares (Malavolta \& Crocomo, 1982). 
Gutierrez et al. (1988) mostram que a aplicação de vinhaça (200 $\mathrm{m}^{3} \cdot \mathrm{ha}^{-1}$ ) como fertilizante, provocou aumento significativo nos teores de potássio e ácido trans-aconítico no caldo de cana-de-açúcar, encontrando correlação positiva significativa entre a produção do ácido trans-aconítico e o teor de potássio.

Orlando $F^{\circ}$. et al. (1993) observaram em trabalho de longa duração (cana-planta e 4 soqueiras subsequentes) que a deficiência de $\mathrm{K}^{+}$não provocou alteração no perfilhamento, mas diminuição da altura e diâmetro dos colmos.

\subsection{Vinhaça $X \mathrm{KCl}$}

Orlando $F^{\circ}$. et al. (1993) com trabalho em Areia Quartzosa variando dosagens de $\mathrm{K}_{2} \mathrm{O}$ de zero a $160 \mathrm{~kg} \mathrm{ha}^{-1}$ no sulco, e em área total até $480 \mathrm{~kg} \cdot$ ha $^{-1}$ concluiram que as fontes $\mathrm{KCl}$ e vinhaça tiveram comportamento semelhante e a ausência de adubação potássica na testemunha absoluta, representando uma deficiência cumulativa de potássio ao longo das socas, indicou menores teores de Pol da cana e maiores de fibra \% cana, sendo as doses de melhores resultados as variantes de 94 a $146 \mathrm{~kg} \mathrm{~K}_{2} \mathrm{O} . \mathrm{ha}^{-1}$.

\subsection{Influência do uso da vinhaça na produtividade da cana-de-açúcar}

Os primeiros trabalhos objetivando a constatação dos efeitos da aplicação da vinhaça "in natura" na lavoura canavieira teriam sido conduzidos por Gomes (1957), que comparou a adubação mineral com diferentes doses de vinhaça, tendo constatado o efeito benéfico da adição do resíduo, em termos de aumento na produtividade, sendo ele corroborado por Almeida (1962), que em trabalho semelhante obteve resultados concordantes, ao aplicar elevadas doses de vinhaça em cana-de-açúcar, em São Paulo. 
Gloria \& Magro (1976), que na Usina da Pedra-SP concluíram que a dose de $35 \mathrm{~m}^{3}$ de vinhaça.ha-1 de mosto de melaço deu melhor resultado que a adubação mineral utilizada para cana-de-açúcar.

Silva et al. (1977) constataram que variedades de cana-de-açúcar respondem diferentemente quando comparados os resultados de parcelas que receberam vinhaça diluida $(1: 10)$ em relação às que não a receberam, tanto no comportamento agroindustrial como na qualidade tecnológica avaliada, sendo a Pol.ha ${ }^{-1}$ nos solos irrigados sempre maior que os não irrigados com vinhaça, conforme dados da tabela 5.

Tabela 5 Produtividade de colmos de cana-de-açúcar e de Pol, em t.haa ${ }^{-1}$, em solo irrigado com vinhaça e não irrigado, para diferentes variedades

\begin{tabular}{|l|c|c|c|c|}
\hline \multirow{2}{*}{ Variedade } & \multicolumn{2}{|c|}{ Produtividade de Cana } & \multicolumn{2}{c|}{ Produtividade de Pol } \\
\cline { 2 - 5 } & Irrigado & Não Irrigado & Irrigado & Não Irrigado \\
\hline CB40 - 13 & 87 & 49 & 12,0 & 8,3 \\
\hline CB46 - 47 & 52 & 40 & 7,4 & 6,8 \\
\hline CB47 - 355 & 72 & 40 & 9,6 & 6,1 \\
\hline CB49 - 62 & 75 & 46 & 9,8 & 6,9 \\
\hline Co740 & 54 & 51 & 7,8 & 8,7 \\
\hline C0775 & 47 & 44 & 7,0 & 7,3 \\
\hline IAC51 - 205 & 97 & 48 & 14,9 & 7,1 \\
\hline IAC52 - 150 & 75 & 48 & 11,9 & 8,1 \\
\hline NA56 - 79 & 97 & 68 & 14,6 & 11,5 \\
\hline
\end{tabular}

Fonte: Silva et al.(1977) 
Stupiello et al. (1977) aplicaram vinhaça em cana-de-açúcar, variedade CB 41-76, $3^{\mathrm{a}}$. soca, em solo Podzólico Vermelho-Amarelo, concluindo que os acréscimos na produtividade obtidos com o uso do resíduo não resultaram em vantagem, no sentido de que a qualidade do caldo ficou muito prejudicado pela diminuição da Pol \% caldo, Brix \% caldo e pureza, além do aumento de cinzas \% caldo e \% Brix, o que acarretaria maiores custos para extração do açúcar.área-1.

Em Copersucar (1978) encontram-se resultados de experimento que buscou avaliar efeitos da aplicação de vinhaça em soqueira de $3^{\circ}$.corte de cana-de-açúcar, variedade CB 41-14, cultivada em solo LVE da Usina São Geraldo/SP, evidenciando que a produtividade de cana e de açúcar tende a aumentar com a aplicação da vinhaça, mesmo em relação à adubação mineral, o mesmo ocorrendo para açúcar por área. Provocou um aumento nas cinzas \% Brix e um decréscimo na pureza aparente. Enquanto que a maturação foi afetada em função da dose de vinhaça utilizada, embora não de modo significativo. Dessa forma pode-se substituir a adubação mineral pelo uso da vinhaça, sem prejuízo. A aplicação de $30 \mathrm{~m}^{3} \cdot \mathrm{ha}^{-1}$ de vinhaça, sem complementação mineral resultou em produtividade $21,4 \%$ maior quando comparada à adubação mineral.

Coleti (1978), em São Paulo, indica que a aplicação de $45 \mathrm{~m}^{3}$ de vinhaça.ha-1 ${ }^{-1}$ de mosto de melaço foi suficiente para a obtenção de altas produções em cana-soca.

Copersucar (1980) em experimento em soqueira de cana-deaçúcar em três anos consecutivos, constatou aumentos na produtividade da mesma proporcionais aos aumentos das dosagens até $90 \mathrm{~m}^{3}$.ha ${ }^{-1}$, com tendência de estabilização e até decréscimo na dosagem mais elevada (180 $\mathrm{m}^{3}$.ha-1) em dois dos três anos considerados.

Rosenfeld et al. (1981) trabalhando em Latossolo Roxo Eutrófico, aplicaram vinhaça diluida com água de lavagem, aplicaram por aspersão doses 
de até $1008 \mathrm{~m}^{3} \cdot \mathrm{ha}^{-1}$, obtendo um acréscimo na produtividade de cana e de açúcar em função aumento nas doses de vinhaça aplicadas.

Baptistella et al. (1981) conduzindo estudo de doses de vinhaça por aspersão em cana-de-açúcar constataram que todos os tratamentos que receberam vinhaça apresentaram maior produtividade em cana e em açúcar.ha' 1 do que aquele que recebeu apenas adubação mineral, sendo que dosagens de $\mathrm{K}_{2} \mathrm{O}$ entre 198 e $308 \mathrm{~kg} . \mathrm{ha}^{-1}$, aplicadas através de 632 e $948 \mathrm{~m}^{3}$ de vinhaça, respectivamente, mostraram melhores resultados.

Marinho et al.(1982) trabalhando com dois tipos de solos em Alagoas aplicaram vinhaça em soqueira de cana-de-açúcar, variedade CB45-3, de primeiro corte, e mostraram que a vinhaça e a adubação mineral provocaram efeitos significativos sobre as produções de cana e de açúcar, nos dois solo estudados ( Podzólico e Latossol). O efeito da vinhaça na ausência de adubação mineral foi muito grande, atingindo valores de até 19,24 toneladas de cana.ha ${ }^{-1}$, com a dose de $135 \mathrm{~m}^{3}$ de vinhaça.ha ${ }^{-1}$, embora não tenha sido suficiente para atingir as produções máximas.

Silva et al. (1983) em experimento com vinhaça seca observaram respostas de aumento linear da produtividade com adição das doses de 1000, 2000 e $3000 \mathrm{~kg}$ de vinhaça seca.ha ${ }^{-1}$, sendo a dose econômica de 2300 kg.ha-1, e que a complementação com adubação fosfatada e nitrogenada em cana soca mostrou ausência de resposta.

Glória \& Orlando Fo. (1983), apresentam resultados de experimentos, realizados por Pexe, na Usina Costa Pinto, e que demonstram não haver diferença entre a produtividade das soqueiras com adubação mineral ou com vinhaça.

Molina et al. (1984) avaliaram o efeito de doses crescentes de vinhaça aplicadas em soqueiras de cana-de-açúcar, na forma de irrigação por aspersão, variando de 0 a $968 \mathrm{~m}^{3} \cdot \mathrm{ha}^{-1}$ (equivalente 0 a $2409 \mathrm{~kg} \mathrm{~K} \mathrm{O} . \mathrm{ha}^{-1}$ ), obtendo aumento na produtividade de cana e açúcar, sendo a melhor dose a de $600 \mathrm{~kg} \mathrm{~K}$ O. ha ${ }^{-1}$. 
2.10 Efeitos do uso da vinhaça na qualidade tecnológica da cana-deaçúcar

Silva et al. (1977) em experimento com diversas variedades de cana-de-açúcar em solo irrigado com vinhaça em comparação com o não irrigado, constataram, em geral, um ganho tanto em produtividade de cana como na quantidade de Pol por hectare em solo irrigado, sendo este da ordem de 8 a 110\%, conforme a variedade estudada. Os mesmos autores observaram que o Brix, a Pol e a pureza aparente apresentam o mesmo comportamento analisando-se em diferentes épocas amostras do experimento, sendo que valores menores no solo irrigado em comparação com o não-irrigado foram encontrados. Ainda, para fibra \% cana verificou-se menor em solo irrigado quando comparado ao não-irrigado, para todas as variedades estudadas, explicada pela maior umidade na planta, reduzindo o percentual fibra. Cinzas \% caldo apresentou-se significativamente mais elevado para parcelas em solo irrigado com vinhaça quando comparado com o não-irrigado, chegando algumas das variedades a apresentar teores cinco vezes superior.

O excesso de matéria orgânica, nitrogênio e principalmente potássio, proveniente da aplicação de pesadas doses de vinhaça, promove problemas no acúmulo de sacarose, sendo que canas oriundas de áreas que receberam vinhaça apresentam teores relativamente baixos de Pol no caldo e aumento em açúcares redutores, indicando assim maior desenvolvimento vegetativo (Rossetto et al., 1977).

Copersucar (1978), estudando efeitos da aplicação de vinhaça em soqueiras de cana-de-açúcar, evidenciaram um aumento nas cinzas \% Brix e um decréscimo na pureza aparente. Observou-se um atraso no início da maturação, que tendeu-se a igualar no decorrer da safra em comparação com canas que receberam só adubação mineral.

Azeredo \& Manhães (1979) concluíram que a dose de $40 \mathrm{~m}^{3}$ de vinhaça.ha ${ }^{-1}$, enriquecida ou não com $\mathrm{P}_{2} \mathrm{O}_{5}$, foi insuficiente para proporcionar 
respostas significativas na produção de cana-soca nas condições do Estado do Rio de Janeiro.

Em Copersucar (1980) é apresentado que em 3 anos consecutivos de aplicação de vinhaça pode-se afirmar que a curva de maturação não foi afetada significativamente em função das doses aplicadas. Confirmando que os teores de $\mathrm{K}$ no caldo sofreram elevação, sem diferença para $P$, obtendo-se aumento na produtividade (t.ha $\left.{ }^{-1}\right)$ de colmos, embora os rendimentos de açúcar recuperável $\mathrm{t}^{-1}$ de cana tenha sofrido decréscimo, enquanto que o rendimento em açúcar.ha ${ }^{-1}$ aumentou até a dose de $90 \mathrm{~m}^{3}$.ha ${ }^{-1}$, estabilizando-se a partir de então.

Silva e Gurgel (1981) realizando experimento com aplicação de vinhaça de mosto misto com e sem complementação mineral, nas dosagens de 40, 80 e $120 \mathrm{~m}^{3} \cdot \mathrm{ha}^{-1}$, em soqueira de cana-de-açúcar, em solo LE, fase Arenosa, constataram que características tecnológicas não foram influenciadas significativamente pelos tratamentos, exceto o teor de cinzas que apresentou-se maior para as maiores dosagens de vinhaça (o,53\% no tratamento com 120 $\mathrm{m}^{3}$.ha $\left.{ }^{-1}\right)$, não chegando porém a atingir valores prejudiciais para a qualidade de açúcar produzido.

Sobral et al. (1981) trabalhando em solo LVA e solo Aqd, em Pernambuco, aplicaram vinhaça de mosto em soqueiras de cana-de-açúcar, variedade CB45-3, e constataram que no solo Latossol Vermelha Amarelo a vinhaça na dose de $50 \mathrm{~m}^{3}$.ha ${ }^{-1}$ resultou em mesma produtividade que a adubação mineral preconizada, enquanto que para tratamentos em solo Areia Quartzosa distrófica o mesmo não ocorreu nem com a maior dose aplicada 400 $\mathrm{m}^{3}$.ha ${ }^{-1}$, embora a respostas tenha sido o dobro da testemunha absoluta. Em termos de Pol.ha-1 não houve diferença estatisticamente significativa entre os tratamentos, o mesmo se dando em relação à fibra \% cana.

Rosenfeld et al. (1981) conduziram experimento com aplicação de vinhaça por aspersão em Latossolo Roxo e constataram que houve uma tendência de redução de valores de AR no caldo(\%). Valores de Pol da cana 
não variaram com o aumento das dosagens de vinhaça, enquanto que os valores de cinzas no caldo (\%) aumentaram linearmente com o aumento das dosagens de vinhaça, variando de $0,28 \%$ no tratamento sem vinhaça, para $0,59 \%$ no tratamento com $1008 \mathrm{~m}^{3} \cdot \mathrm{ha}^{-1}$ de vinhaça diluida.

Baptistella et al. (1981) conduzindo estudo de doses de vinhaça por aspersão em cana-de-açúcar constataram que com o aumento das dosagens diminuiu o teor de AR e a Pol da cana, ocorrendo um aumento no teor de cinza no caldo extraído.

A adubação mineral causou efeitos depressivos significativos sobre a Pol da cana e a pureza do caldo em ensaios realizados em Alagoas, com doses de 45,90, $135 \mathrm{~m}^{3} \cdot \mathrm{ha}^{-1}$ com e sem complementação mineral e adubação mineral recomendada. (Marinho et al.,1982).

A elevação na produtividade da cana-de-açúcar, evidenciada pela aplicação de vinhaça ocorre em consequência de um maior desenvolvimento vegetativo, ocasionado pela adição ao solo de matéria orgânica e elementos minerais, notadamente o potássio. Em vista disso, o processo de maturação e a qualidade tecnológica da cana-de-açúcar podem ser afetadas, principalmente com o uso de doses elevadas desse resíduo. (Silva, 1982).

Glória \& Orlando $F^{\circ}$. (1983), citando trabalhos de diversos autores, constatam que o uso de doses racionais de vinhaça (40 a $60 \mathrm{~m}^{3} . \mathrm{ha}^{-1}$ ) não prejudicam significativamente a Pol do caldo e que, em consequência do aumento da produtividade agrícola, aumenta a produção de açúcar.ha ${ }^{-1}$.

Molina et al. (1984) comparando a dosagem de $600 \mathrm{~kg}$ de $\mathrm{K}_{2} \mathrm{O} \cdot \mathrm{ha}^{-1}$, aplicado pela vinhaça em irrigação por aspersão com a adubação recomendada constataram um acréscimo de $3 \%$ na Pol da cana , $1 \%$ na pureza e nenhuma alteração nos valores da fibra. 


\section{MATERIAL E MÉTODOS}

\subsection{Localização do experimento}

O experimento foi instalado em área do Departamento de Agroindustria, Alimentos e Nutrição, da ESALQ/USP, situada no Município de Piracicaba, Estado de São Paulo, cujas coordenadas geográficas médias são: $22^{\circ} 42^{\prime}$ de Latitude Sul e $42^{\circ} 25^{\prime}$ de Longitude Oeste, situada a 580 m de altitude, sendo a aplicação dos fertilizantes no campo e a coleta de matéria-prima no período de setembro/1996 a outubro/1997.

\subsection{Clima}

A região onde localiza-se 0 experimento apresenta clima característico do tipo CWA (Koeppen), tropical úmido, com inverno seco (junho a agosto), verão chuvoso e quente.

A figura 1 apresenta o gráfico elaborado a partir de dados fornecidos pelo Departamento de Física e Meteorologia da ESALQ/USP mostra o histórico de precipitação e de evaporação estimada para o período de maio 
de 1996 a outubro de 1997 para o posto meteorológico dessa instituição, localizado próximo ao campo do experimento em questão.

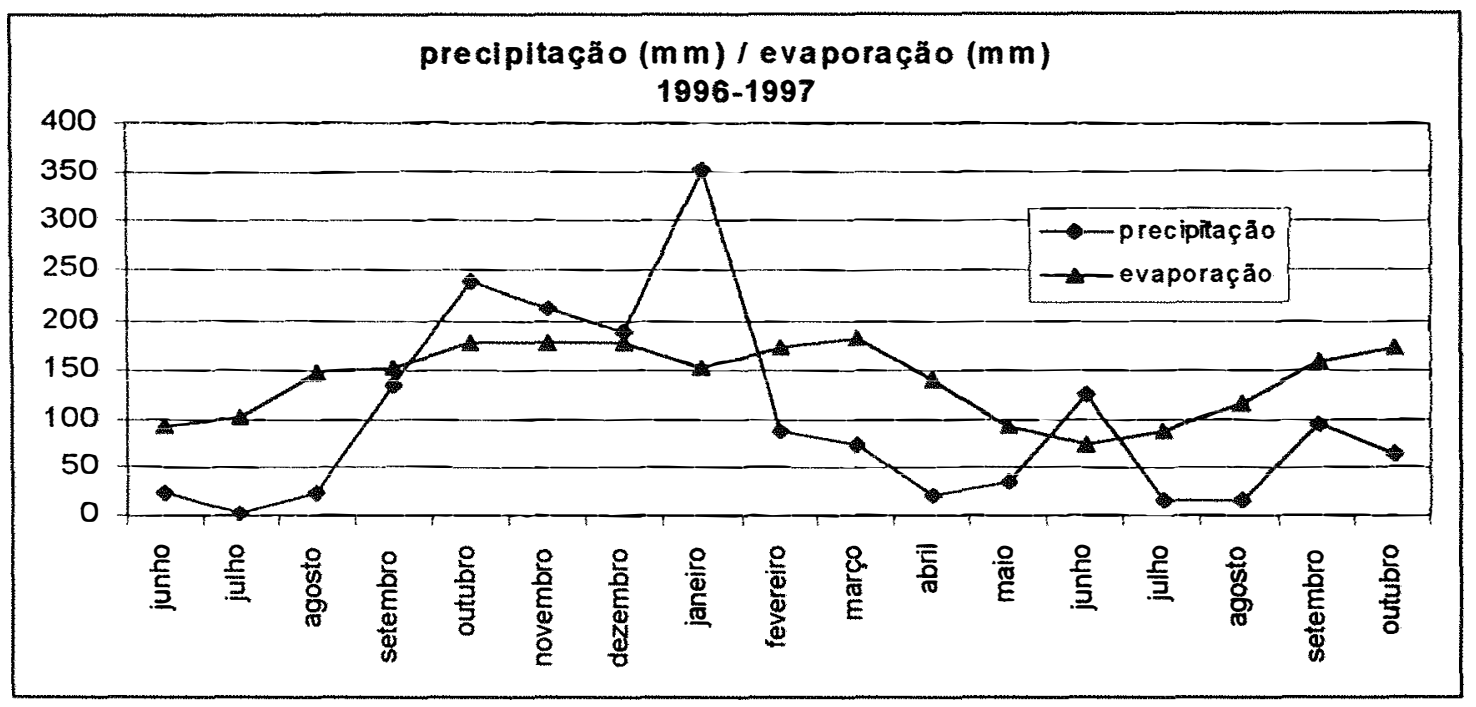

Figura 1: Precipitação e evaporação, em mm, para a região do experimento

\subsection{Cana-de-açúcar}

A cana-soca utilizada é da variedade RB78-5148, que apresenta alta produtividade agrícola e bom comportamento em solos de baixa fertilidade, resistência à ferrugem e reação intermediária ao carvão, mosaico e escaldadura das folhas. É tolerante ao raquitismo. É de maturação média, com boa capacidade de perfilhamento, rápido fechamento das entrelinhas e excelente brotação de soqueira, e de crescimento ereto, capitel aberto , com pequena quantidade de folhas. O palmito é médio e a despalha é fácil. (Usineiro, mai/jun.1988). 


\subsection{Composição da vinhaça}

Os dados da análise da composição da vinhaça diluida de mosto de caldo, proveniente da destilaria do Departamento de Agroindustria, Alimentos e Nutrição, realizada pelo laboratório do Departamento de Solos e Nutrição de Plantas, da ESALQ, encontram-se na tabela 6, em apêndice, página 43 , e revelou ser um material rico em potássio e em matéria orgânica.

\subsection{Nivel de fertilidade do solo}

O solo da área do experimento é caracterizado como TE - Terra Roxa Estruturada, Eutrófica, Amoderado, Textura argilosa, muito argilosa (Kandiudalfic Eutrudox). A amostragem foi tomada na entre linha da soqueira, a $20 \mathrm{~cm}$ acima da soqueira, na profundidade de $0-40 \mathrm{~cm}$, e sua análise foi realizada no laboratório de solos AFOCAPI/COPLACANA, utilizando $\mathrm{H}_{2} \mathrm{SO}_{4}$ $0,5 \mathrm{~N}$ como extrator. Os resultados encontram-se na tabela 7 , em apêndice, página 43 , o que permite afirmar tratar-se de um solo de fertilidade média.

\subsection{Adubação mineral recomendada}

Em Orlando $F^{\circ}$. (1983) encontra-se a recomendação de adubação potássica para a região Centro-Sul, estabelecida por Rodella et al. (1981), e que é apresentada na tabela 8 . 
Tabela 8.Recomendação de adubação potássica ( $\mathrm{em} \mathrm{kg} \mathrm{K} \mathrm{K}_{2} \mathrm{O} \mathrm{ha}^{-1}$ ), em função da classe de fertilidade do solo e da relação $w^{-t^{-1}}$ ( preço $t$ cana.preço kg nutriente ${ }^{-1}$ ).

\begin{tabular}{|c|c|c|c|c|c|}
\hline \multicolumn{6}{|c|}{ classes de fertilidade } \\
\hline & $\begin{array}{l}\text { muito } \\
\text { baixa }\end{array}$ & baixa & média & alta & Muito alta \\
\hline & $\begin{array}{c}<40 \\
\mathrm{mg} \cdot \mathrm{dm}^{-3} \mathrm{~K}\end{array}$ & $\begin{array}{c}40-80 \\
\mathrm{mg} \cdot \mathrm{dm}^{-3} \mathrm{~K}\end{array}$ & $\begin{array}{c}80-130 \\
\mathrm{mg} \cdot \mathrm{dm}^{-3} \mathrm{~K}\end{array}$ & $\begin{array}{l}130-260 \\
\mathrm{mg} \cdot \mathrm{dm}^{-3} \mathrm{~K}\end{array}$ & $\begin{array}{c}>260 \\
\mathrm{mg} \cdot \mathrm{dm}^{-3} \mathrm{~K}\end{array}$ \\
\hline$w \cdot t^{-1}$ & & & $\left(\mathrm{~kg} \mathrm{~K}_{2} \mathrm{O} \cdot \mathrm{ha}\right.$ & & \\
\hline 20 & 170 & 140 & 90 & 60 & $0-50$ \\
\hline 25 & 190 & 160 & 100 & 70 & $0-50$ \\
\hline 30 & 200 & 170 & 110 & 80 & $0-50$ \\
\hline
\end{tabular}

Fonte: Orlando Fo. (1983)

Esses resultados indicam uma adubação mineral em cobertura, de $500 \mathrm{~kg} \cdot \mathrm{ha}^{-1}$ da formulação $20-05-20(\mathrm{~N}-\mathrm{P}-\mathrm{K})$.

\subsection{Instalação do experimento}

O ensaio de campo foi instalado em outubro/96, em área já identificada acima. $O$ delineamento experimental foi o de parcelas, em blocos ao acaso, com três repetições de onze tratamentos, sendo eles:

$$
\begin{aligned}
& T 1=\text { testemunha absoluta; } \\
& T 2=100 \mathrm{~m}^{3} \cdot h a^{-1} \text { de vinhaça; } \\
& T 3=200 \mathrm{~m}^{3} \cdot h a^{-1} \text { de vinhaça; } \\
& T 4=300 \mathrm{~m}^{3} \cdot h a^{-1} \text { de vinhaça; } \\
& T 5=400 \mathrm{~m}^{3} \cdot \text { ha }^{-1} \text { de vinhaça; }
\end{aligned}
$$


T6 = $500 \mathrm{~kg} \cdot \mathrm{ha}^{-1}$ da fórmula 20-05-20 (N-P-K);

$\mathrm{T} 7=248 \mathrm{~kg} \cdot \mathrm{ha}^{-1} \mathrm{KCl}$;

$\mathrm{T} 8=100 \mathrm{~m}^{3} \cdot \mathrm{ha}^{-1}$ de vinhaça $+186 \mathrm{~kg} \cdot \mathrm{ha}^{-1} \mathrm{KCl}$;

$\mathrm{T} 9=200 \mathrm{~m}^{3} \cdot \mathrm{ha}^{-1}$ de vinhaça $+124 \mathrm{~kg} \cdot \mathrm{ha}^{-1} \mathrm{KCl}$;

$\mathrm{T} 10=300 \mathrm{~m}^{3} \cdot$ ha ${ }^{-1}$ de vinhaça $+62 \mathrm{~kg} \cdot \mathrm{ha}^{-1} \mathrm{KCl}$;

$\mathrm{T} 11=500 \mathrm{~kg} \cdot \mathrm{ha}^{-1}$ da fórmula 20-05-20 (N-P-K) + $148 \mathrm{~kg} \cdot \mathrm{ha}^{-1}$ $\mathrm{KCl}$.

A escolha dessa dosagens de vinhaça deveu-se à quantidade de potássio recomendada para o nível de fertilidade do solo, dada pela análise do mesmo. Procurou-se estabelecer uma equivalência dos teores de potássio na vinhaça, e então aplicar doses crescentes nas parcelas, ou seja, aproximadamente da metade até 0 dobro dose recomendada. Essa quantidade extraordinária de vinhaça tem como objetivo a verificação de seu efeito nas qualidades da cana-soca, uma vez que existe a necessidade de um grande descarte desse resíduo. Os níveis de $\mathrm{KCl}$ aplicados estão em paralelo à máxima quantidade de potássio levada pela vinhaça, conforme tabela 9.

Tabela 9. Quantidades de $\mathrm{K}_{2} \mathrm{O}$ na vinhaça aplicada no experimento

\begin{tabular}{|c|c|c|c|c|}
\hline \multirow[b]{2}{*}{ vinhaça $\left(\mathrm{m}^{3} \cdot h \mathrm{a}^{-1}\right)$} & \multicolumn{4}{|c|}{ doses aplicadas } \\
\hline & 100 & 200 & 300 & 400 \\
\hline $\begin{array}{l}\text { equivalente em } \\
\mathrm{K}_{2} \mathrm{O}\left(\mathrm{kg} \mathrm{ha}^{-1}\right)\end{array}$ & 62 & 124 & 186 & 248 \\
\hline
\end{tabular}


Cada parcela é constituida de 5 linhas de cana-de-açúcar, $10,00 \mathrm{~m}$ de comprimento e espaçamento entre linhas de 1,40 m. A vinhaça foi aplicada, por gravidade, em área total das 3 linhas centrais da parcela, compreendendo um total de $42,00 \mathrm{~m}^{2}$. parcela ${ }^{-1}$. Foi distribuido, a lanço, $\mathrm{KCl}$ em metade das parcelas ( $4 \mathrm{~m}$ úteis $+1 \mathrm{~m}$ de bordadura), conforme exigência de cada tratamento acima descrito. O solo foi cultivado mecanicamente para evitar a mato-competição, até o fechamento das ruas.

\subsection{Amostragem e preparo para análise laboratorial}

O desenvolvimento da cana-de-açúcar foi acompanhado, a partir do mês de junho, com amostragem mensal, composta de 10 colmos colhidos na mesma linha, sendo esta sorteada. Despalhada, mas com ponta, as amostras de cada parcela foram encaminhadas ao laboratório do Setor de Açúcar e Álcool do Departamento de Agroindustria, Alimentos e Nutrição da ESALQ/USP, onde foram pesadas inteiras e depois pesadas despontadas. Estas foram desintegradas, e homogeneizadas com auxílio de betoneira, sendo então retirada uma porção para pesagem de $500 \mathrm{~g}$ que foram prensadas em prensa hidráulica, seguindo técnica de Tanimoto (1964) para obtenção do bagaço prensado e do caldo extraído (CE), que foi analisado nos seguintes parâmetros:

3.8.1 Brix do $\mathrm{CE}$; determinado por refratometria a $20^{\circ} \mathrm{C} / 20^{\circ} \mathrm{C}$ (Schneider, 1979)

3.8.2 Pol do CE; dosada pelo método de Schmitz sem diluição, segundo ICUMSA (Schneider, 1979);

3.8.3 Açúcares redutores do CE (AR \% CE), expressos em açúcares invertidos, dosados pelo método de Lane \& Eynon (1934); 
3.8.4 Peso do bagaço úmido fibroso da prensa (PBU), através da pesagem do resíduo fibroso úmido (R1) resultante da prensagem ,

3.8.5 Peso do bagaço seco fibroso da prensa (PBS), obtido através da pesagem do resíduo fibroso seco (R2), até peso constante a temperatura de $105-110^{\circ} \mathrm{C}$, em estufa com circulação forçada de ar.

3.8.7 Cinzas Condutimétricas \% CE, dosadas em rafinômetro, como indicado por Browne \& Zerban (1941);

\subsection{Cálculos com os parâmetros obtidos}

3.9.0 Pureza aparente CE, calculada pela relação: Pol CE. Brix $\mathrm{CE}^{-1} \times 100$;

3.9.1 Fibra \% cana $(F)$, utilizada a metodologia de Tanimoto (1964), adaptada por Sturion \& Fernandes (1979), segundo a fórmula:

$$
F=\frac{100 x(R 2-R 1) x B r i x C E}{5 x(100-B r i x C E)}
$$

3.9.2 Brix da cana; segundo Sturion \& Fernandes (1979), através da expressão:

$$
\text { Brix da cana }=\text { Brix CE } \times \text { FB }
$$

onde, $F B=1,01083-0,01240 \times F$

3.9.3 Pol da cana; segundo Sturion \& Fernandes (1979), através da expressão: 
Pol da cana $=$ Pol CE $\times$ FS

onde, $F S=0,94283-0,010469 \times F$

3.9.4 Açúcares Redutores \% cana (AR\% cana),: convertido pelas fórmulas de Tanimoto (1964) em AR \% cana, como em César \& Silva (1993),

$$
A R \% \text { cana }=A R \% \text { CE } \times F S
$$

3.9.5 Pureza, segundo a expressão em César \& Silva (1993),

$$
P z=\left(\text { Pol da cana. Brix da cana }{ }^{-1}\right) \cdot 100 ;
$$

3.9.6 Cinzas Condutimétricas, como indicado por Browne \& Zerban (1941);

$$
\text { Cinzas \% caldo }=L \pm 0,022(T-20) \times L
$$

Onde: L é a leitura obtida no rafinômetro; e T é a temperatura da amostra na leitura.

3.9.8 Umidade da cana, calculada como indicado por Spencer \& Meade (1932), pela expressão:

$$
U \%=100 \times(\text { Brix cana }+ \text { Fibra \% cana })
$$

3.9.9 Açúcar total recuperado por hectare, pela expressão em César \& Silva (1993):

$$
A T R(\mathrm{~kg} / \text { ton })=(10 x S-0,76 x F-6,9) x\left((5 / 3)-\frac{200}{3 x(P Z A-1)}\right.
$$

onde, $\mathrm{S}=$ Pol da cana 
3.10 Cálculos de parâmetros agronômicos:

3.10.1 Teor de matéria verde (ponta), através de pesagem direta das amostras e extrapolação para peso.ha" ${ }^{-1}$;

3.10.2 Produção de colmos por hectare (número e peso), através de pesagem direta das amostras e extrapolação para peso.ha-1. 


\section{RESULTADOS E DISCUSSÃO}

O delineamento experimental adotado foi 0 de parcelas inteiramente ao acaso, subdividida no tempo, com 11 tratamentos. Os resultados obtidos são médias de três repetições de cada tratamento, analisados mensalmente entre os meses de junho a outubro. Os coeficientes de variação situam-se entre 0,642 a 21,00\%, estando ainda dentro de limites toleráveis para fins de experimentação agrícola, em condições de campo aberto, segundo Gomes (1985). Para analise da variância empregou-se o Teste $\mathrm{F}$ e para os contrastes entre médias o Teste de Tuckey, cujos resultados são apresentados nas respectivas tabelas de cada parâmetro considerado, como segue.

\subsection{Brix da cana}

Importante indicador do estágio de maturação da cana-deaçúcar, principalmente quando correlacionado com outros parâmetros, como açúcares redutores e Pol. Ele apresentou neste experimento um comportamento esperado ao longo das épocas, quer seja, o de aumento de valores como o passar das épocas, em vista do amadurecimento da cana-deaçúcar. 
Para a mesma época, as médias dos tratamentos apresentaram algumas variações, principalmente para as épocas iniciais, apresentando uma tendência a se igualarem até a época da colheita, como se observa na tabela 10. Os valores apresentaram-se entre 13,98 e 16,59 \%, e quando aplicado o teste $\mathrm{F}$ mostrou valor significativo ao nivel de $1 \%$ de probabilidade nos meses de junho (T7 e T11), julho(T2 e T11) e agosto(T2 e T6) e a 5\% em outubro (T6 e T8).

Tais resultados permitem afirmar que não é significativo o efeito dos tratamentos no processo de acumulação de sólidos solúveis na cana-deaçúcar, concordando com o observado por diversos autores citados em revisão.

Tabela 10 Comparação das médias para Brix da cana, para o mês de outubro

\begin{tabular}{|c|c|c|c|c|c|c|c|c|c|c|}
\hline \multirow{2}{*}{$\begin{array}{l}\text { TRATA- } \\
\text { MENTO }\end{array}$} & \multicolumn{2}{|c|}{ JUNHO } & \multicolumn{2}{|c|}{ JULHO } & \multicolumn{2}{|c|}{ AGOSTO } & \multicolumn{2}{|c|}{ SETEMBRO } & \multicolumn{2}{|c|}{ OUTUBRO } \\
\hline & MEDIAS & $5 \% \quad 1 \%$ & MEDIAS & $5 \% \quad 1 \%$ & MEDIAS & $5 \% \quad 1 \%$ & MEDIAS & $5 \% \quad 1 \%$ & MEDIAS & $\begin{array}{c}5 \% \\
1 \%\end{array}$ \\
\hline T1 & 15,11 & $a b c A B$ & 14,15 & $C B C$ & 15,18 & b $A B$ & 16,30 & a $\mathrm{A}$ & 15,87 & $a b A$ \\
\hline$T 2$ & 14,65 & $b c A B$ & 13,98 & $c \quad c$ & 14,97 & b B & 16,08 & a $A$ & 15,81 & $a b A$ \\
\hline T3 & 14,98 & $a b c A B$ & 14,28 & $b c A B C$ & 15,31 & $a b A B$ & 16,47 & a $A$ & 16,04 & $a b A$ \\
\hline $\mathrm{T} 4$ & 15,10 & $a b c A B$ & 14,18 & bc $B C$ & 15,21 & $a b A B$ & 16,28 & a $A$ & $16, \infty$ & $a b A$ \\
\hline T5 & 15,23 & $a b c A B$ & 14,13 & c $B C$ & 15,11 & b $A B$ & 15,68 & a $A$ & 15,71 & ab A \\
\hline T6 & 15,81 & $a b \quad A B$ & 14,85 & $a b \quad A B$ & 15,90 & a $\mathrm{A}$ & $16, \infty$ & a $\mathrm{A}$ & 16,57 & a $A$ \\
\hline$T 7$ & 14,43 & C $B$ & 14,23 & $b c A B C$ & 15,30 & ab $A B$ & 16,13 & a $\mathrm{A}$ & 15,92 & $a b A$ \\
\hline T8 & 15,10 & $a b c A B$ & 14,32 & $b c A B C$ & 15,14 & b $A B$ & 16,01 & a $A$ & 15,52 & b A \\
\hline T9 & $15, \infty$ & $a b c A B$ & 14,46 & $a b c A B C$ & 15,40 & $a b A B$ & 15,85 & a $\mathrm{A}$ & 15,80 & $a b A$ \\
\hline T10 & 14,68 & bc $A B$ & 14,48 & $a b c A B C$ & 15,15 & $b A B$ & 16,31 & a $\mathrm{A}$ & 15,90 & $a b A$ \\
\hline $\mathrm{T} 11$ & 16,16 & a $\mathrm{A}$ & $15, \infty 0$ & a $\mathrm{A}$ & 15,53 & $a b A B$ & 16,56 & a $A$ & 16,59 & a $\mathrm{A}$ \\
\hline
\end{tabular}

D.M.S. $5 \%=0.94286-$ D.M.S. $1 \%=1.13758$

Coeficiente de Variação $=2.020 \%$ Prob $>F: 0.01188$ 
À época da colheita os valores médios de Brix apresentaram-se muito semelhantes quando comparados os tratamentos que não receberam complementação de $\mathrm{KCl}$ com aqueles que os receberam. A figura 2, apresenta a comparação dos gráficos dos tratamentos, assim como suas equações, evidenciando uma tendência maior de aumento dos teores de Brix para os tratamentos que receberam a complementação com KCl.

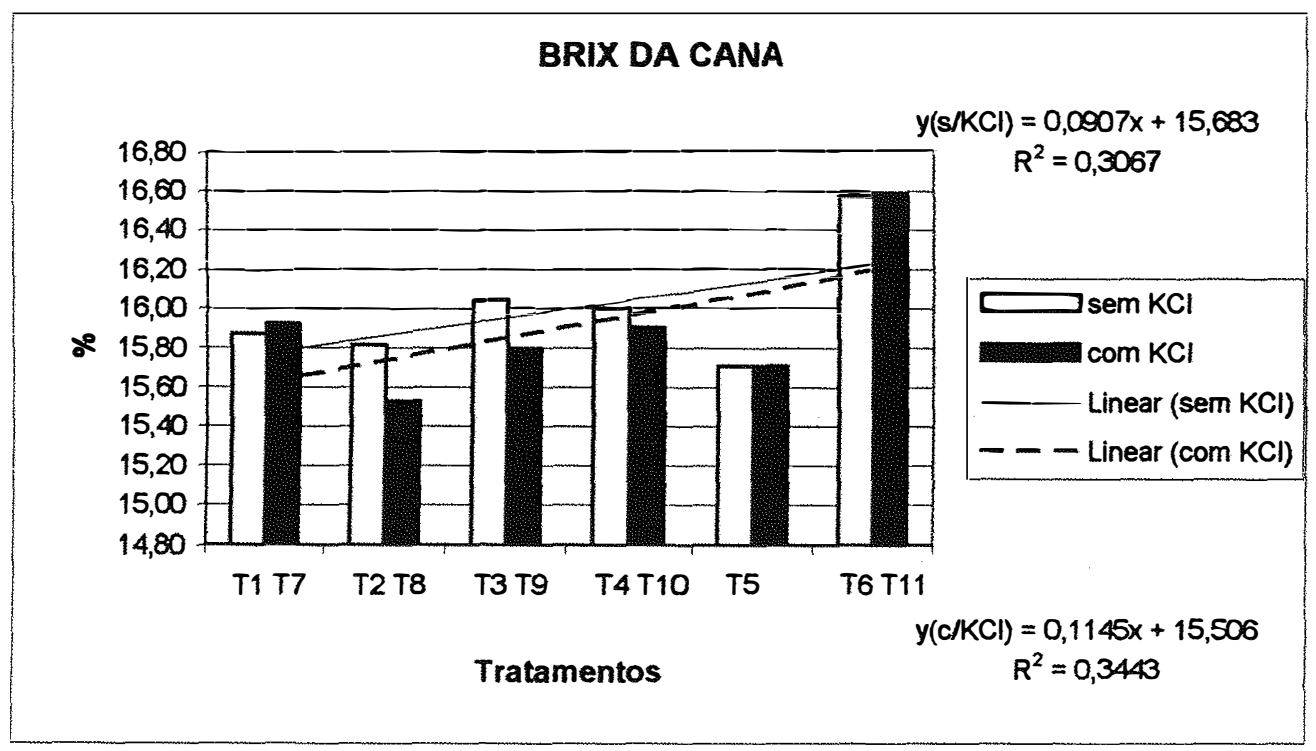

Figura 2 Comparação das médias de Brix da cana, para o mês de outubro, apresentando as linhas de tendência e suas equações ajustadas

\subsection{Pol da cana}

A Pol é um parâmetro indicativo da quantidade de sacarose na cana, e quando correlacionado com Brix permite uma estimativa do estágio 
ideal de maturação e pureza da cana-de-açúcar para obtenção de maior rendimento industrial.

A análise estatística dos dados mostrou que somente no mês de julho os dados apresentaram variações significativas a $1 \%$ para os tratamentos T11 e T2, enquanto que para os demais meses os valores apresentaram-se significativos a $5 \%$, para os tratamentos que apresentaram alguma variação. Somente é possível afirmar que, independente dos tratamentos, os valores de Pol tenderam a aumentar ao longo das épocas amostradas, conforme observado nos dados da tabela 11, acompanhando o comportamento do Brix.

Tabela 11: Comparação das médias para Pol da cana, para o mês de outubro

\begin{tabular}{|c|c|c|c|c|c|c|c|c|c|c|}
\hline \multirow{2}{*}{$\begin{array}{l}\text { TRATA- } \\
\text { MENTO }\end{array}$} & \multicolumn{2}{|c|}{ JUNHO } & \multicolumn{2}{|c|}{ JULHO } & \multicolumn{2}{|c|}{ AGOSTO } & \multicolumn{2}{|c|}{ SETEMBRO } & \multicolumn{2}{|c|}{ OUTUBRO } \\
\hline & MEDIAS & $5 \% \quad 1 \%$ & MEDIAS & $5 \% \quad 1 \%$ & MEDIAS & $5 \% \quad 1 \%$ & MEDIAS & $5 \% \quad 1 \%$ & MEDIAS & $5 \% \quad 1 \%$ \\
\hline T1 & 12,97 & $a b c A$ & 12,31 & bc $A B C$ & 13,75 & a A & 14,44 & $a b A$ & $14, \infty$ & $a b A$ \\
\hline T2 & 12,57 & bc $A$ & 12,01 & c C & 13,26 & a $\mathrm{A}$ & 14,19 & $a b A$ & 14,10 & $a b A$ \\
\hline T3 & 12,91 & $a b c A$ & 12,42 & abc $A B C$ & 13,48 & a $A$ & 14,55 & $a b A$ & 14,24 & ab $A$ \\
\hline T4 & 13,04 & $a b c A$ & 12,26 & C $A B C$ & 13,48 & a $A$ & 14,36 & $a b A$ & 14,12 & $a b A$ \\
\hline T5 & 13,06 & $a b c A$ & 12,15 & C $B C$ & 13,28 & a $A$ & 13,67 & $\mathrm{~b} A$ & 13,75 & b A \\
\hline T6 & 13,74 & $a b A$ & 13,02 & $a b \quad A B$ & 13,86 & a $\mathrm{A}$ & 14,82 & a $\mathrm{A}$ & 14,66 & ab $A$ \\
\hline$T 7$ & 12,50 & C A & 12,30 & bc $A B C$ & 13,46 & a $\mathrm{A}$ & 14,30 & $a b A$ & 14,14 & $a b A$ \\
\hline T8 & 13,02 & abc $A$ & 12,38 & abc $A B C$ & 13,24 & a $A$ & 14,33 & $a b A$ & 13,79 & $a b A$ \\
\hline T9 & 13,22 & $a b c A$ & 12,44 & abc $A B C$ & 13,52 & a A & 14,01 & $a b A$ & 14,08 & $a b A$ \\
\hline T10 & 12,70 & bc $A$ & 12,45 & $a b c \quad A B C$ & 13,24 & a A & 14,41 & $a b A$ & 14,11 & $a b A$ \\
\hline T11 & 13,92 & a $\mathrm{A}$ & 13,06 & A & 13,61 & a $\mathrm{A}$ & 14,69 & $a b A$ & 14,75 & \\
\hline
\end{tabular}

D.M.S. $5 \%=0.96061-$ D.M.S. $1 \%=1.15899$

Coeficiente de Variação $=2.321 \%$

Prob.>F : 0.03137

Quantidades maiores de vinhaça resultaram em menores valores de Pol na cana, enquanto que maiores doses de potássio via mineral resultaram em maiores valores. Esse fato pode ser entendido por um efeito de diluição pela maior retenção de água quando de doses maiores de vinhaça foram utilizadas. Diferindo, inclusive estatisticamente a nivel de $5 \%$, quando na 
época da colheita são comparados os tratamentos T5 (maior dose de vinhaça) com $\mathrm{T} 11$ ( maior dose de $\mathrm{KCl}$ ), sendo que este último apresentou 1,14 ponto percentual a menos de umidade. Diferença que não é acompanhada quando analisada a pureza ou mesmo o potássio no caldo.

Quando comparados os tratamento entre si, observa-se que o tratamento com adubação mineral recomendada (T6) foi sempre maior que os demais. $E$, quando comparados os tratamentos que receberam complementação com $\mathrm{KCl}$ com aqueles que não o receberam, observa-se pela linha de tendência um maior ângulo de inclinação para os tratamentos com complementação, conforme o gráfico da figura 3. Por ocasião da última amostragem (outubro) a Pol da cana, assim como o ATR, para os tratamentos que receberam vinhaça, estiveram menores que o tratamento que recebeu adubação mineral, complementada ou não com $\mathrm{KCl}$, e próximos ao valor apresentado pela testemunha absoluta. Enquanto que, de modo geral, a complementação da vinhaça com $\mathrm{KCl}$ não mostrou resultado positivo.

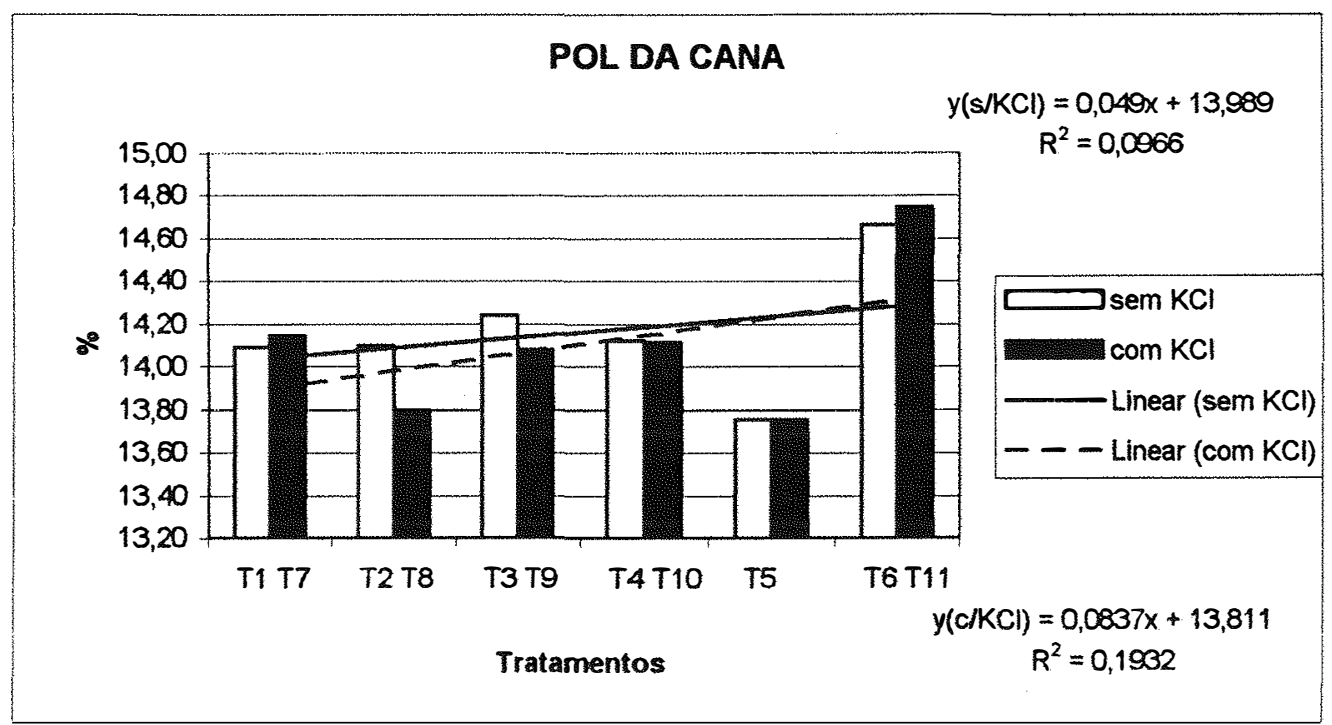

Figura 3 : Comparação das médias de Pol da cana, para o mês de outubro, apresentando as linhas de tendência e suas equações ajustadas 


\subsection{Pureza}

Foi um parâmetro que apresentou menor coeficiente de variação e entre épocas e/ou tratamentos não foi constatada diferenças significativas nem a nível de $5 \%$, exceto no mês de setembro para os tratamentos T5 e T8, num comportamento isolado.

Entretanto, observa-se uma tendência de queda nos valores de pureza com o aumento das doses de vinhaça, de acordo com trabalhos de Stupiello et al. (1977) e Silva (1985). Enquanto que a adubação preconizada mostrou pureza maior que a maior dose de vinhaça aplicada, embora menor que a maior quantidade de $\mathrm{KCl}(\mathrm{T} 11)$, o que pode ser entendido como um favorecimento ao acúmulo de sacarose em presença de maior quantidade de potássio. Tal diferença de T5 para T6 é de 0,95 ponto percentual, e de 1,34 de T11 para T5, o que pode ser significativo a nível de rendimento industrial. A comparação das médias é apresentada na tabela 12.

Tabela 12 Comparação das médias para Pureza \% cana, para o mês de outubro

\begin{tabular}{|c|c|c|c|c|c|c|c|c|c|c|}
\hline \multirow{2}{*}{$\begin{array}{l}\text { TRATA- } \\
\text { MENTO }\end{array}$} & \multicolumn{2}{|c|}{ JUNHO } & \multicolumn{2}{c|}{ JULHO } & \multicolumn{2}{c|}{ AGOSTO } & \multicolumn{2}{c|}{ SETEMBRO } & \multicolumn{2}{c|}{ OUTUBRO } \\
\cline { 2 - 14 } & MEDIAS & $5 \%$ 1\% & MEDIAS & $5 \%$ 1\% & MEDIAS & $5 \% 1 \%$ & MEDIAS & $5 \% 1 \%$ & MEDIAS & $5 \%$ 1\% \\
\hline T1 & 85,84 & a A & 87,00 & a A & 90,56 & a A & 88,55 & ab A & 88,81 & a A \\
\hline T2 & 85,79 & a A & 85,94 & a A & 88,60 & a A & 88,27 & ab A & 89,15 & a A \\
\hline T3 & 86,18 & a A & 87,00 & a A & 88,05 & a A & 88,37 & ab A & 88,79 & a A \\
\hline T4 & 86,36 & a A & 86,46 & a A & 88,62 & a A & 88,16 & ab A & 88,27 & a A \\
\hline T5 & 85,72 & a A & 85,96 & a A & 87,90 & a A & 87,12 & b A & 87,53 & a A \\
\hline T6 & 86,92 & a A & 87,68 & a A & 87,19 & a A & 88,77 & ab A & 88,48 & a A \\
\hline T7 & 86,62 & a A & 86,47 & a A & 87,96 & a A & 88,64 & ab A & 88,85 & a A \\
\hline T8 & 86,19 & a A & 86,50 & a A & 87,50 & a A & 89,47 & a A & 88,84 & a A \\
\hline T9 & 87,56 & a A & 86,02 & a A & 87,75 & a A & 88,36 & ab A & 89,10 & a A \\
\hline T10 & 86,54 & a A & 86,06 & a A & 87,37 & a A & 88,32 & ab A & 88,74 & a A \\
\hline T11 & 86,16 & a A & 87,05 & a A & 87,64 & a A & 88,70 & ab A & 88,87 & a A \\
\hline
\end{tabular}

D.M.S. $5 \%=1.66403$ - D.M.S. $1 \%=2.00768$

Coeficiente de Variação $=0.642 \%$

Prob. $>F \quad 0.09922$ 
A figura 4, mostra o gráfico comparativo dos tratamentos com e sem complementação com $\mathrm{KCl}$, evidenciando pela linha de tendência uma queda mais acentuada de pureza para os tratamentos que não receberam a complementação .

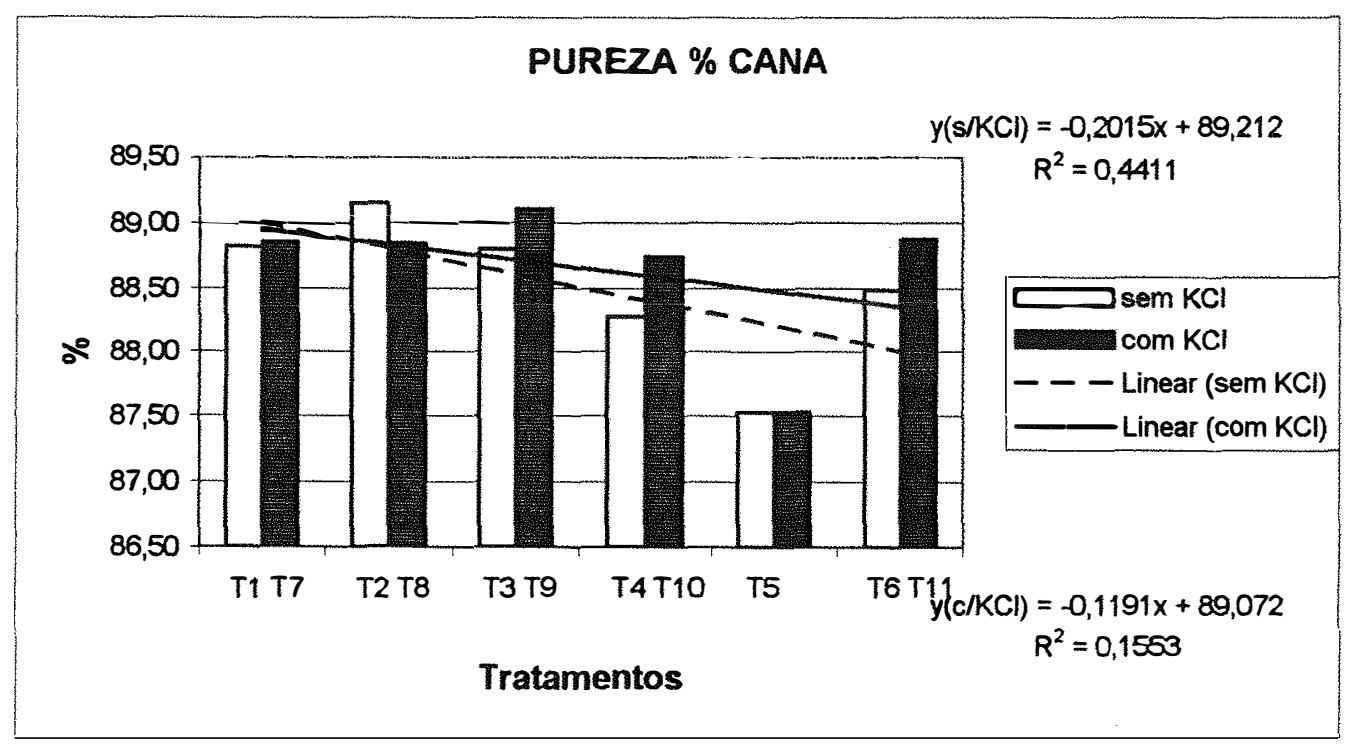

Figura 4 : Comparação das médias de Pureza \% cana, para o mês de outubro, apresentando as linhas de tendência e suas equações ajustadas

\subsection{Açúcares redutores}

$\mathrm{Na}$ comparação das médias de açúcares redutores, apresentada na tabela 13, nada de significativo foi encontrado, entre os tratamentos em qualquer época. Embora se observe que os maiores valores estão para os tratamentos que mais receberam vinhaça. No geral, é clara a tendência de queda nos valores de $A R$ ao longo das épocas, o que não foi afetado por nenhum dos tratamentos. 
Tabela 13: Comparação das médias para açúcares redutores, para o mês de outubro

\begin{tabular}{|c|c|c|c|c|c|c|c|c|c|c|}
\hline \multirow{2}{*}{$\begin{array}{l}\text { TRATA- } \\
\text { MENTO }\end{array}$} & \multicolumn{2}{|c|}{ JUNHO } & \multicolumn{2}{|c|}{ JULHO } & \multicolumn{2}{|c|}{ AGOSTO } & \multicolumn{2}{|c|}{ SETEMBRO } & \multicolumn{2}{|c|}{ OUTUBRO } \\
\hline & MEDIAS & $5 \% \quad 1 \%$ & MEDIAS & $5 \% \quad 1 \%$ & MEDIAS & $5 \% \quad 1 \%$ & MEDIAS & $5 \% 1 \%$ & MEDIAS & $5 \% 19$ \\
\hline T1 & 0,28 & a $\mathrm{A}$ & 0,13 & a $\mathrm{A}$ & 0,18 & a $\mathrm{A}$ & 0,12 & a $\mathrm{A}$ & 0,12 & a $\mathrm{A}$ \\
\hline T2 & 0,29 & a $A$ & 0,14 & a A & 0,19 & a $\mathrm{A}$ & 0,16 & a A & 0,11 & a $\mathrm{A}$ \\
\hline T3 & 0,26 & a $\mathrm{A}$ & 0,13 & a $\mathrm{A}$ & 0,18 & a A & 0,13 & a A & 0,12 & a $\mathrm{A}$ \\
\hline T4 & 0,24 & a $\mathrm{A}$ & 0,13 & a $A$ & 0,17 & a A & 0,13 & a $\mathrm{A}$ & 0,11 & a $\mathrm{A}$ \\
\hline T5 & 0,26 & a $\mathrm{A}$ & 0,13 & a $A$ & 0,18 & a A & 0,18 & a $\mathrm{A}$ & 0,13 & a $\mathrm{A}$ \\
\hline T6 & 0,23 & a $\mathrm{A}$ & 0,14 & a $\mathrm{A}$ & 0,15 & a $\mathrm{A}$ & 0,14 & a $\mathrm{A}$ & 0,13 & a $\mathrm{A}$ \\
\hline $\mathrm{T} 7$ & 0,18 & a $\mathrm{A}$ & 0,11 & a $\mathrm{A}$ & 0,14 & a $\mathrm{A}$ & 0,09 & a $\mathrm{A}$ & 0,12 & a $\mathrm{A}$ \\
\hline T8 & 0,20 & a $\mathrm{A}$ & 0,12 & a $A$ & 0,16 & a $\mathrm{A}$ & 0,12 & a $\mathrm{A}$ & 0,10 & a $\mathrm{A}$ \\
\hline T9 & 0,20 & a $\mathrm{A}$ & 0,14 & a $\mathrm{A}$ & 0,16 & a $\mathrm{A}$ & 0,12 & a A & 0,10 & a $A$ \\
\hline T10 & 0,19 & a $\mathrm{A}$ & 0,13 & a A & 0,16 & a A & 0,09 & a A & 0,10 & a $\mathrm{A}$ \\
\hline T11 & 0,22 & a A & 0,13 & a $A$ & 0,16 & a A & 0,10 & a $\mathrm{A}$ & 0,09 & a A \\
\hline
\end{tabular}

D.M.S. $5 \%=0.06917-$ D.M.S. $1 \%=0.08346$

Coeficiente de Variação $=21.004 \%$

Prob.>F : 0.45856

Os tratamentos que receberam complementação com $\mathrm{KCl}$ apresentam teores de açúcares redutores com discreta tendência de queda em relação aos que não a receberam, em geral da ordem de 0,02 pontos percentuais, conforme observado na figura 5 , que também traz as respectivas equações das linhas de tendência. 


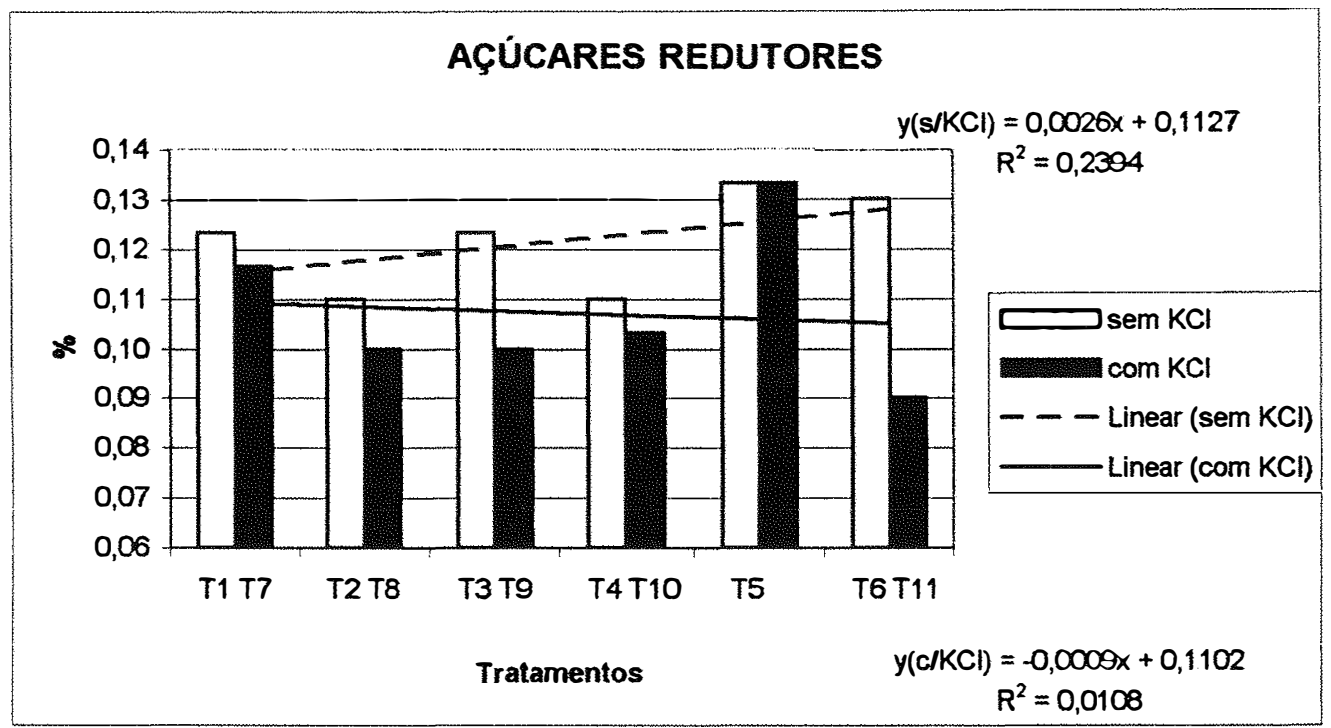

Figura 5 : Comparação das médias de Açúcares Resdutores \% cana, para o mês de outubro, apresentando as linhas de tendência e suas equações ajustadas

\subsection{Fibra e umidade na cana}

Conforme os dados das tabelas 14 e 15, apesar do baixo coeficiente de variação, a única diferença significativa a $5 \%$ encontrada foi a de fibra \% cana, no mês de agosto entre os tratamentos T2 e T6, isoladamente, o que evidencia que os tratamentos não afetam tais parâmetros da qualidade da cana. Embora, os números possam sugerir que a adição de vinhaça favoreça um decréscimo em fibra, como se observa para os tratamentos com doses mais elevadas de vinhaça (T4 e T5), quando comparados a T1 e a T6, testemunha absoluta e adubação mineral preconizada, respectivamente.

Os valores das tabelas evidenciam uma diminuição na umidade e aumento de fibra \% cana para todos os tratamentos no transcorrer das épocas das análises. 
Tabela 14 Comparação das médias para Umidade \% cana, para o mês de outubro

\begin{tabular}{|l|c|c|c|c|c|c|c|c|c|c|c|}
\hline \multirow{2}{*}{$\begin{array}{l}\text { TRATA- } \\
\text { MENTO }\end{array}$} & \multicolumn{2}{|c|}{ JUNHO } & \multicolumn{2}{c|}{ JULHO } & \multicolumn{2}{c|}{ AGOSTO } & \multicolumn{2}{c|}{ SETEMBRO } & \multicolumn{2}{c|}{ OUTUBRO } \\
\cline { 2 - 15 } & MEDIAS & $5 \% 1 \%$ & MEDIAS & $5 \%$ 1\% & MEDIAS & $5 \% 1 \%$ & MEDIAS & $5 \%$ 1\% & MEDIAS & $5 \%$ 1\% \\
\hline T1 & 70,55 & a A & 70,56 & a A & 69,37 & a A & 66,74 & a A & 67,68 & a A \\
\hline T2 & 70,58 & a A & 71,33 & a A & 69,00 & a A & 67,55 & a A & 67,94 & a A \\
\hline T3 & 70,36 & a A & 70,64 & a A & 69,19 & a A & 67,22 & a A & 68,11 & a A \\
\hline T4 & 70,03 & a A & 71,07 & a A & 69,46 & a A & 67,31 & a A & 67,87 & a A \\
\hline T5 & 71,35 & a A & 71,40 & a A & 70,13 & a A & 69,33 & a A & 68,95 & a A \\
\hline T6 & 70,00 & a A & 70,42 & a A & 69,71 & a A & 67,57 & a A & 67,97 & a A \\
\hline T7 & 69,84 & a A & 70,82 & a A & 69,28 & a A & 67,60 & a A & 67,95 & a A \\
\hline T8 & 71,28 & a A & 70,15 & a A & 69,20 & a A & 67,80 & a A & 67,94 & a A \\
\hline T9 & 70,50 & a A & 70,65 & a A & 69,28 & a A & 67,65 & a A & 68,01 & a A \\
\hline T10 & 6,09 & a A & 70,58 & a A & 69,27 & a A & 67,30 & a A & 68,22 & a A \\
\hline T11 & 70,82 & a A & 70,18 & a A & 69,08 & a A & 67,28 & a A & 67,81 & a A \\
\hline
\end{tabular}

D.M.S. $5 \%=2.67987-$ D.M.S. $1 \%=3.23332$

Coeficiente de Variação $=1.348 \%$

Prob.>F : 0.93179

Tabela 15 Comparação das médias para Fibra \% cana, para o mês de outubro

\begin{tabular}{|l|c|c|c|c|c|c|c|c|c|c|c|c|}
\hline \multirow{2}{*}{$\begin{array}{l}\text { TRATA } \\
\text { MENTO }\end{array}$} & \multicolumn{2}{|c|}{ JUNHO } & \multicolumn{2}{c|}{ JULHO } & \multicolumn{2}{c|}{ AGOSTO } & \multicolumn{2}{c|}{ SETEMBRO } & \multicolumn{2}{c|}{ OUTUBRO } \\
\cline { 2 - 14 } & MEDIAS & $5 \% 1 \%$ & MEDIAS & $5 \% 1 \%$ & MEDIAS & $5 \% 1 \%$ & MEDIAS & $5 \%$ 1\% & MEDIAS & $5 \%$ & $1 \%$ \\
\hline T1 & 14,34 & a A & 15,29 & a A & 15,44 & ab A & 16,96 & a A & 16,46 & a A \\
\hline T2 & 14,76 & a A & 14,69 & a A & 16,03 & a A & 16,37 & a A & 16,25 & a A \\
\hline T3 & 14,67 & a A & 15,08 & a A & 15,51 & ab A & 16,31 & a A & 15,85 & a A \\
\hline T4 & 14,87 & a A & 14,75 & a A & 15,32 & ab A & 16,41 & a A & 16,14 & a A \\
\hline T5 & 13,41 & a A & 14,48 & a A & 14,76 & ab A & 14,99 & a A & 15,34 & a A \\
\hline T6 & 14,19 & a A & 14,73 & a A & 14,40 & b A & 15,73 & a A & 15,46 & a A \\
\hline T7 & 15,73 & a A & 14,95 & a A & 15,43 & ab A & 16,27 & a A & 16,12 & a A \\
\hline T8 & 13,61 & a A & 15,53 & a A & 15,66 & ab A & 16,19 & a A & 16,53 & a A \\
\hline T9 & 14,41 & a A & 14,89 & a A & 15,32 & ab A & 16,49 & a A & 16,19 & a A \\
\hline T10 & 16,24 & a A & 14,95 & a A & 15,58 & ab A & 16,38 & a A & 15,88 & a A \\
\hline T11 & 13,02 & a A & 14,83 & a A & 15,39 & ab A & 16,16 & a A & 15,60 & a A \\
\hline
\end{tabular}

D.M.S. $5 \%=2.29564$ - D.M.S. $1 \%=2.76974$

Coeficiente de Variação $=4.916 \%$

Prob.>F : 0.67100 
$\mathrm{Na}$ comparação entre os tratamentos com e sem complementação como $\mathrm{KCl}$ observa-se que quase não há diferença entre eles, entretanto a linha de tendência evidencia uma maior queda nos valores de fibra $\%$ cana para os tratamentos que não receberam complementação com $\mathrm{KCl}$, conforme a figura 6 .

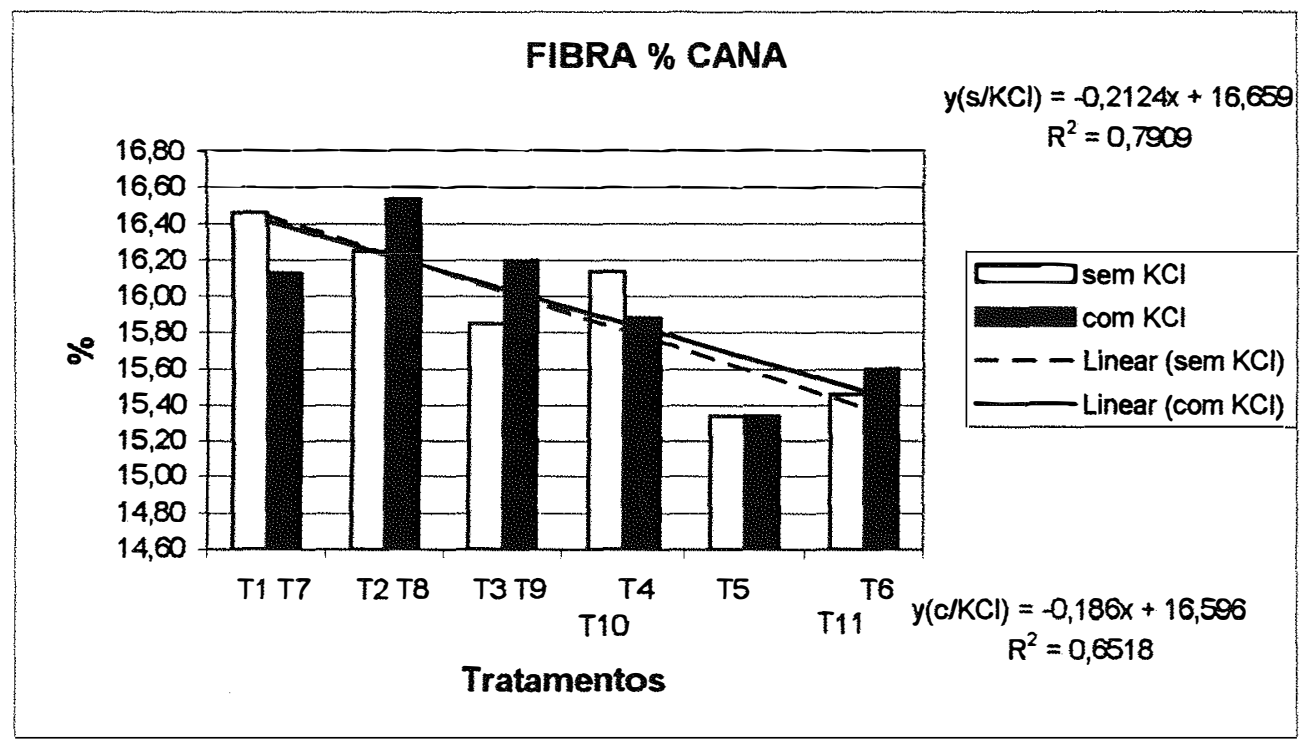

Figura 6 : Comparação das médias de Fibra \% cana, para o mês de outubro, apresentando as linhas de tendência e suas equações ajustadas

\subsection{Potássio e Cinzas}

É bem conhecido o efeito melassigênico do potássio no caldo, assim como o fato de ser o componente em maior quantidade nas cinzas. Portanto, sendo a vinhaça rica nesse elemento é de se esperar que os tratamentos que receberam maiores quantidades do mesmo, via vinhaça ou na forma de $\mathrm{KCl}$, apresentem maiores teores de cinzas no caldo. Contudo, como apresentado na tabela 16, mesmo com um coeficiente de variação de 15,376 
$\%$, na época da colheita do experimento (outubro), a nível de $5 \%$ não foi encontrado diferença entre os tratamentos, muito embora maiores doses de vinhaça acarretarem maiores teores de potássio no caldo.

Tabela 16 Comparação das médias para $\mathrm{K}_{2} \mathrm{O}\left(\mathrm{mg}^{\mathrm{L}} \mathrm{L}^{-1}\right)$ no caldo da cana, para o mês de outubro

\begin{tabular}{|l|c|l|l|l|l|l|l|l|l|l|l|}
\hline $\begin{array}{l}\text { TRATA. } \\
\text { MENTO }\end{array}$ & \multicolumn{2}{|c|}{ JUNHO } & \multicolumn{2}{c|}{ JULHO } & \multicolumn{2}{c|}{ AGOSTO } & \multicolumn{2}{c|}{ SETEMBRO } & \multicolumn{2}{c|}{ OUTUBRO } \\
\cline { 2 - 14 } & MEDIAS & $5 \%$ 1\% & MEDIAS & $5 \%$ 1\% & MEDIAS & $5 \%$ 1\% & MEDIAS & $5 \%$ 1\% & MEDIAS & $5 \%$ 1\% \\
\hline T1 & 3496 & a A & 2751 & ab A & 2853 & ab AB & 2108 & ab A & 2237 & a A \\
\hline T2 & 3548 & a A & 3188 & ab A & 2854 & ab AB & 2288 & ab A & 1928 & a A \\
\hline T3 & 3342 & a A & 2673 & ab A & 2879 & ab AB & 2416 & ab A & 2108 & a A \\
\hline T4 & 3393 & a A & 3188 & ab A & 3136 & a AB & 2365 & ab A & 2493 & a A \\
\hline T5 & 4062 & a A & 3162 & ab A & 3342 & a A & 2828 & a A & 2853 & a A \\
\hline T6 & 2828 & a A & 2211 & b A & 2185 & b B & 1928 & b A & 1953 & a A \\
\hline T7 & 3805 & a A & 3419 & a A & 2956 & ab AB & 2674 & ab A & 2314 & a A \\
\hline T8 & 3393 & a A & 3393 & a A & 2853 & ab AB & 2468 & ab A & 2134 & a A \\
\hline T9 & 3445 & a A & 3496 & a A & 2931 & ab AB & 2365 & ab A & 2211 & a A \\
\hline T10 & 3547 & a A & 3573 & a A & 3110 & ab AB & 2751 & ab A & 2236 & a A \\
\hline T11 & 2982 & a A & 2879 & ab A & 2403 & ab AB & 2134 & ab A & 1980 & a A \\
\hline
\end{tabular}

D.M.S. $5 \%=998.25591-$ D.M.S. $1 \%=1204.41746$

Coeficiente de Variação $=15.376 \%$

Prob. $>F: 0.11037$

Também se constata que a mesma quantidade de potássio via vinhaça produziu uma quantidade de $\mathrm{K}_{2} \mathrm{O}$ no caldo, muito maior $(44 \%)$ que quando aplicado via $\mathrm{KCl}$ (figura 7). 


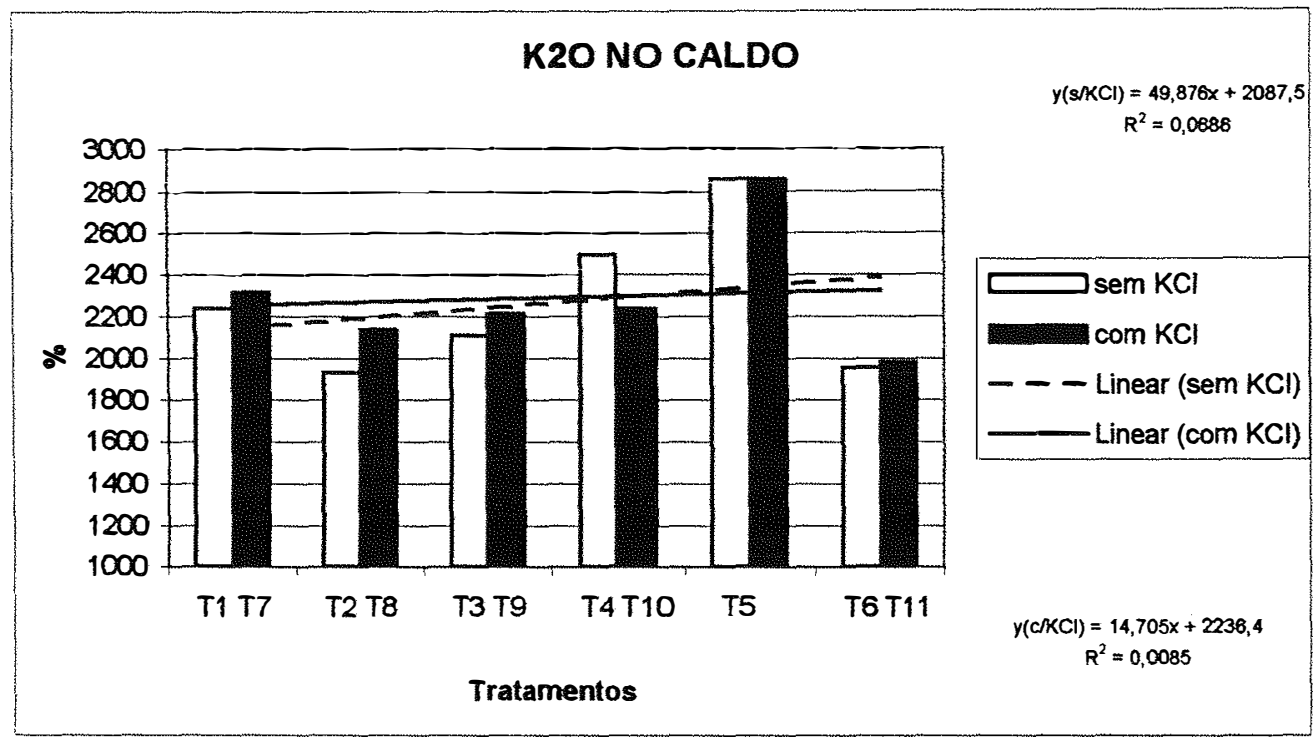

Figura 7 : Comparação das médias de $\mathrm{K}_{2} \mathrm{O}$ no caldo, para o mês de outubro, apresentando as linhas de tendência e suas equações ajustadas

Tendência observada para estes parâmetros de qualidade da cana-de-açúcar é que diferenças mais acentuadas entre os tratamentos são observadas nas épocas iniciais das amostragens. Todavia, vão se atenuando com o transcorrer dos meses, o que pode estar relacionado a uma maior demanda de potássio para o desenvolvimento vegetativo, já que as parcelas que receberam mais vinhaça foram também as que apresentaram maior peso em pontas à época da colheita do experimento.

Cinzas \% caldo acompanham rigorosamente o comportamento apresentado para $\mathrm{K}_{2} \mathrm{O}$ no caldo . Ou seja, maior aplicação de potássio, maior a absorção pela planta, o que pode ser justificado pelo fato da cana-de-açúcar apresentar absorção de luxo para esse elemento. Ele vai para o caldo compor as cinzas, seja ele aplicado na forma mineral como via vinhaça. Embora, nesta última, os teores de cinzas no caldo sejam maiores, diferença esta que tende a 
diminuir com o passar das épocas, ou seja, na última amostragem (outubro) a diferença nos teores de cinzas entre a adubação mineral e com vinhaça (equivalente em potássio) era bem menor que no início das amostragens, como se constata na tabela 17.

Tabela 17 Comparação das médias para Cinzas \% no caldo, para o mês de outubro

\begin{tabular}{|c|c|c|c|c|c|c|c|c|c|c|}
\hline \multirow{2}{*}{$\begin{array}{l}\text { TRATA- } \\
\text { MENTO }\end{array}$} & \multicolumn{2}{|c|}{ JUNHO } & \multicolumn{2}{|c|}{ JULHO } & \multicolumn{2}{|c|}{ AGOSTO } & \multicolumn{2}{|c|}{ SETEMBRO } & \multicolumn{2}{|c|}{ OUTUBRO } \\
\hline & MEDIAS & $5 \% \quad 1 \%$ & MEDIAS & $5 \% \quad 1 \%$ & MEDIAS & $5 \% 1 \%$ & MEDIAS & $5 \% \quad 1 \%$ & MEDIAS & $5 \% 1 \%$ \\
\hline T1 & 0,68 & $a b c A B$ & 0,65 & $a b A B C$ & $0, \varpi 3$ & $A b A B$ & 0,49 & b $B$ & 0,53 & a $\mathrm{A}$ \\
\hline T2 & 0,71 & $a b c A B$ & 0,72 & ab $A B C$ & 0,66 & $A b A B$ & 0,54 & $a b A B$ & 0,49 & a $A$ \\
\hline T3 & 0,70 & $a b c A B$ & 0,70 & $a b A B C$ & 0,65 & $A b A B$ & 0,55 & $a b A B$ & 0,51 & a $A$ \\
\hline T4 & 0,76 & $a b \quad A B$ & 0,77 & a $A B C$ & 0,71 & a $A B$ & 0,56 & $a b A B$ & 0,60 & \\
\hline T5 & 0,79 & a A & 0,79 & a $A B$ & 0,75 & a $\mathrm{A}$ & 66 & a $\mathrm{A}$ & 0,65 & a $A$ \\
\hline T6 & 0,59 & $C B$ & 0,59 & b c & 0,53 & b $B$ & 0,49 & b $B$ & 0,50 & a $\mathrm{A}$ \\
\hline T7 & 0,75 & $a b \quad A B$ & 0,67 & $a b A B C$ & 0,69 & a $A B$ & $0, \mathfrak{3}$ & a $A B$ & 0,57 & a $A$ \\
\hline T8 & 0,72 & $a b c A B$ & 0,68 & $a b A B C$ & 0,67 & $A b A B$ & 0,60 & $a b A B$ & 0,56 & \\
\hline T9 & 0,72 & $a b c A B$ & 0,68 & $a b A B C$ & 0,68 & a $A B$ & 0,59 & $a b A B$ & 0,57 & a $\mathrm{A}$ \\
\hline $\mathrm{T} 10$ & 0,78 & a A & 0,79 & a A & 0,73 & a $\mathrm{A}$ & 0,65 & a $\mathrm{A}$ & 0,55 & a $A$ \\
\hline T11 & 0,64 & bc $A B$ & 0,60 & b $B C$ & 0,61 & $A b A B$ & 0,55 & $a b A B$ & 0,51 & a A \\
\hline
\end{tabular}

D.M.S. $5 \%=0.16897-$ D.M.S. $1 \%=0.20387$

Coeficiente de Variação $=10.528 \%$

Prob. $>F$ : 0.09636

Enquanto a figura 8, apresenta $\circ$ gráfico com as linhas de tendência, evidenciando que praticamente não há diferença entre eles, exceto um ângulo de inclinação pouco maior para os tratamentos sem complementação com $\mathrm{KCl}$, observado na comparação dos teores de $\mathrm{K}_{2} \mathrm{O}$ no caldo da cana. 


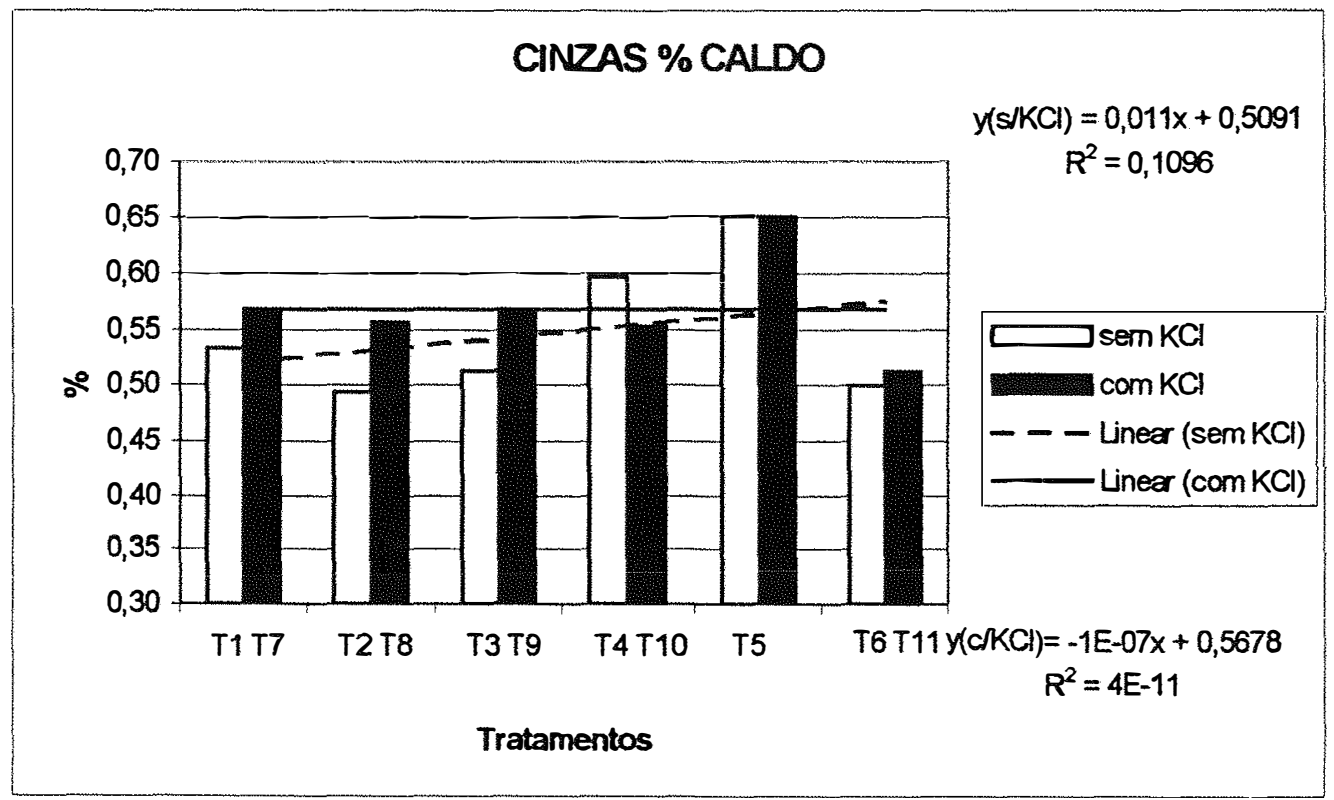

Figura 8 : Comparação das médias de Cinzas \% no caldo, para o mês de outubro, apresentando as linhas de tendência e suas equaçöes ajustadas

\subsection{Açúcar Teórico Recuperável}

A medida que amadurece a cana-de-açúcar, as diferenças entre os tratamentos, que já são pouco significativas, tendem a diminuir (tabela 18). Somente a $5 \%$ é que a diferença é significativa nos mês de outubro para os tratamentos T5 e T11, que chega a $9,45 \%$ maior para $T 11$, e $8,49 \%$ para T6. Mesmo sem análise estatística não é possível afirmar diferença entre os demais tratamentos. 
Tabela 18 Comparação das médias para Açúcar Teórico Recuperável, para o mês de outubro

\begin{tabular}{|c|c|c|c|c|c|c|c|c|c|c|}
\hline \multirow{2}{*}{$\begin{array}{c}\text { TRATA } \\
\text { MENTO }\end{array}$} & \multicolumn{2}{|c|}{ JUNHO } & \multicolumn{2}{|c|}{ JULHO } & \multicolumn{2}{c|}{ AGOSTO } & \multicolumn{2}{c|}{ SETEMBRO } & \multicolumn{2}{c|}{ OUTUBRO } \\
\cline { 2 - 14 } & MEDIAS & $5 \%$ 1\% & MEDIAS & $5 \%$ 1\% & MEDIAS & $5 \%$ 1\% & MEDIAS & $5 \%$ 1\% & MEDIAS & $5 \%$ 1\% \\
\hline T1 & 102,86 & Ab A & 97,07 & bc ABC & 113,75 & a A & 116,99 & ab A & 114,44 & ab A \\
\hline T2 & 98,78 & Ab A & 93,83 & c C & 106,83 & a A & 114,88 & ab A & 114,97 & ab A \\
\hline T3 & 102,37 & Ab A & 98,30 & abc ABC & 108,72 & a A & 118,42 & ab A & 116,37 & ab A \\
\hline T4 & 103,58 & Ab A & 96,6 & c ABC & 109,46 & a A & 116,28 & ab A & 114,45 & ab A \\
\hline T5 & 104,29 & Ab A & 95,32 & c BC & 107,40 & a A & 110,05 & b A & 110,93 & b A \\
\hline T6 & 111,19 & Ab A & 104,79 & a A & 112,37 & a A & 121,91 & a A & 120,35 & ab A \\
\hline T7 & 98,05 & b A & 96,78 & c ABC & 108,51 & a A & 116,34 & ab A & 115,25 & ab A \\
\hline T8 & 104,25 & Ab A & 97,10 & bc ABC & 105,88 & a A & 117,51 & ab A & 111,61 & b A \\
\hline T9 & 106,81 & Ab A & 97,65 & abc ABC & 109,00 & a A & 113,20 & ab A & 114,81 & ab A \\
\hline T10 & 99,46 & Ab A & 97,82 & abc ABC & 105,78 & a A & 116,97 & ab A & 115,05 & ab A \\
\hline T11 & 113,06 & a A & 104,41 & ab AB & 109,63 & a A & 120,20 & ab A & 121,41 & a A \\
\hline
\end{tabular}

D.M.S. $5 \%=9.53466-$ D.M.S. $1 \%=11.50378$

Coeficiente de Variação $=2.828 \%$

PROB. $>F: 0.02204$

O gráfico comparativo dos tratamentos com e sem complementação com $\mathrm{KCl}$, apresentado na figura 9, apresenta uma linha de tendência mais ascendente para os tratamentos com complementação com $\mathrm{KCl}$. 


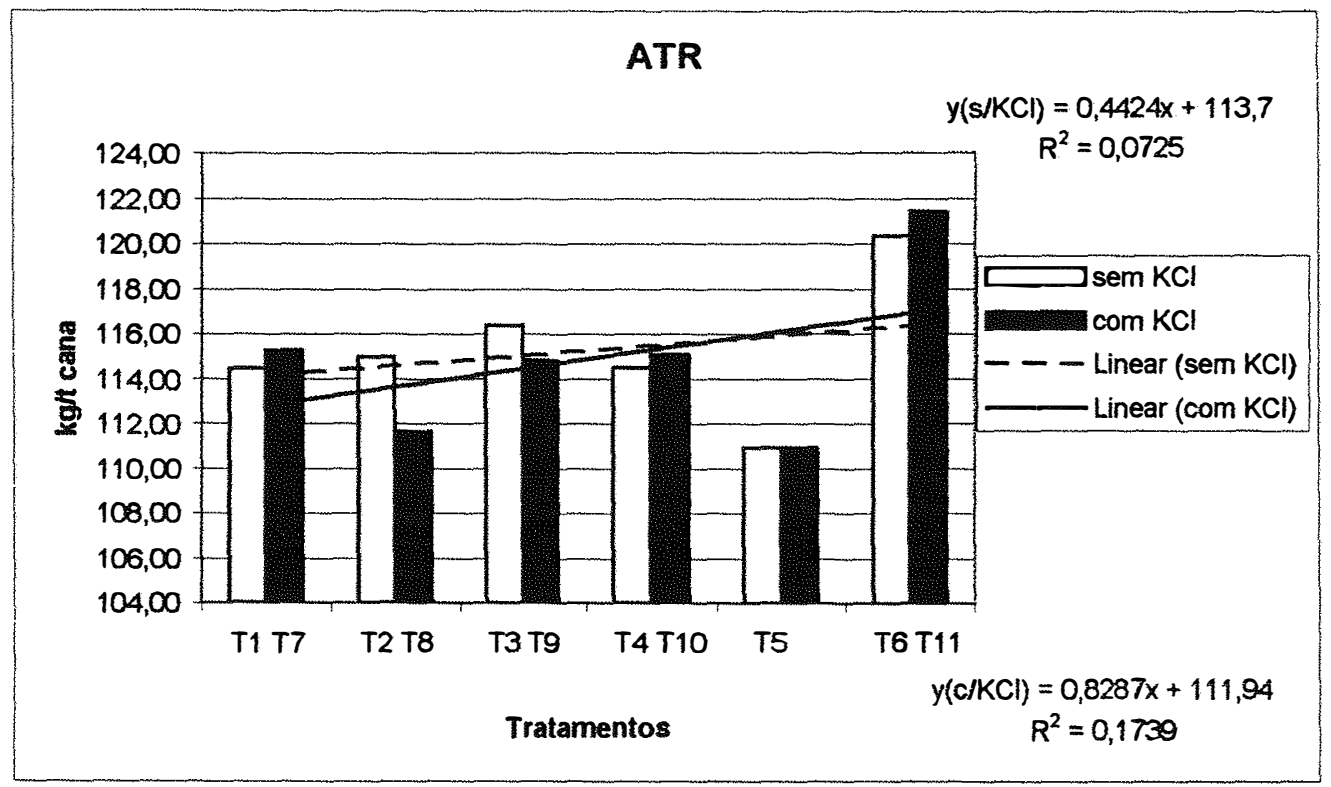

Figura 9: Comparação das médias de ATR (kg/t cana), para o mês de outubro, apresentando as linhas de tendência e suas equaçöes ajustadas

\subsection{Produtividade agrícola}

A massa despontada cresceu acompanhando o crescimento do desenvolvimento vegetativo proporcionado pelo acréscimo de fertilizantes dado pela vinhaça aplicada ou pela adubação mineral fornecida, em comparação com a testemunha absoluta. Entretanto, parcelas que receberam complementação com $\mathrm{KCl}$ resultaram em menor massa de desponte, em todos os tratamentos. As linhas de tendência apresentam-se paralelas, como observa-se no gráfico da figura 10. 


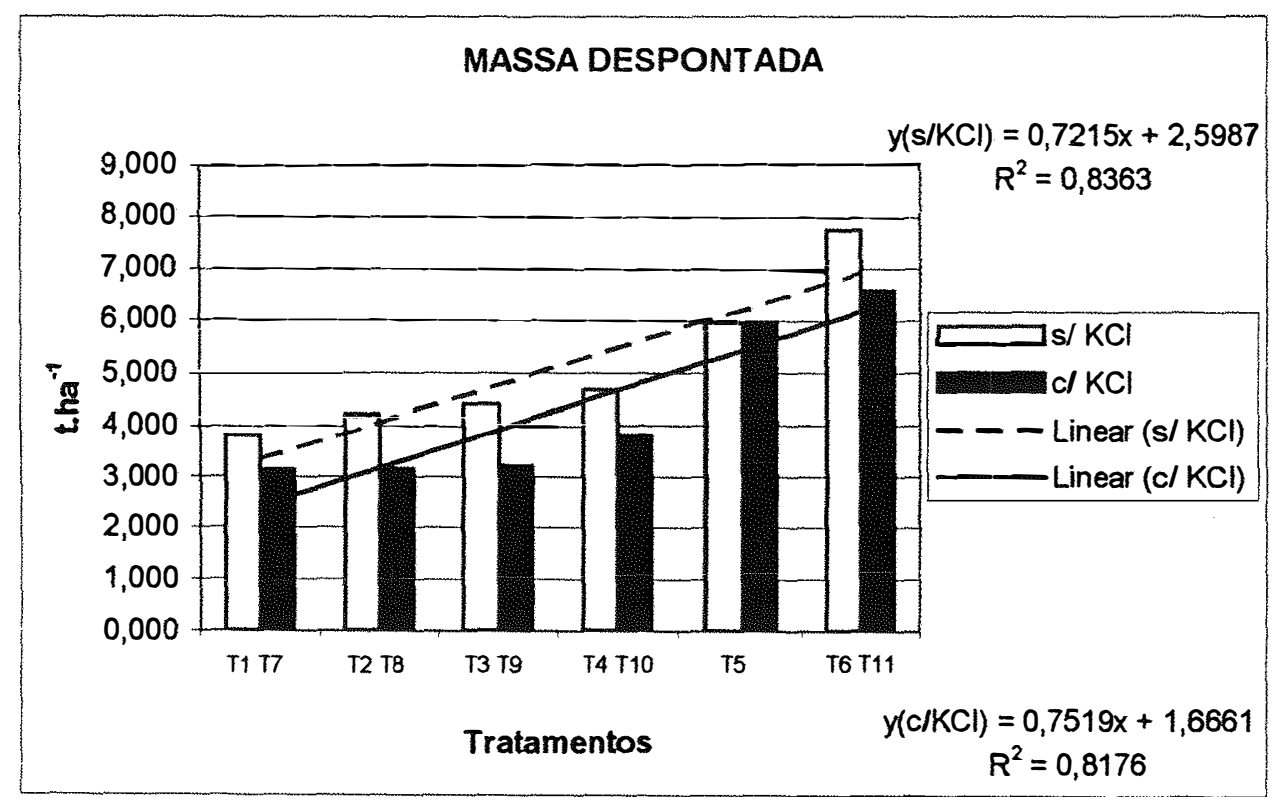

Figura 10: Comparação das médias de massa despontada, para o mês de outubro, apresentando as linhas de tendência e suas equações ajustadas

Um maior teor de potássio, fornecido via $\mathrm{KCl}$, favoreceu um deslocamento de nutrientes da parte vegetativa para a formação e acúmulo de sacarose na cana. Na planta este potássio será parte essencial do processo de síntese proteica e na translocação e armazenamento de açúcares; ainda, o potássio é participante da ativação de enzimas, e assim seu nível na planta determina o crescimento da mesma, interferindo não só na massa vegetal como também no acúmulo de açúcares, como observado por Glória (1985). Os dados são apresentados no tabela 19. 
Tabela 19 Desponte e a diferença entre tratamentos complementados e não com KCl

\begin{tabular}{|c|c|c|c|c|}
\hline \multicolumn{2}{|c|}{ Tratamento sem KCl } & \multicolumn{2}{c|}{ Tratamento com KCl } & Diferença \\
\hline T1 & 3,804 & T7 & 3,121 & 0,683 \\
\hline T2 & 4,184 & T8 & 3,135 & 1,049 \\
\hline T3 & 4,396 & T9 & 3,202 & 1,194 \\
\hline T4 & 4,667 & T10 & 3,802 & 0,865 \\
\hline T5 & 6,196 & T1 & 3,804 & 2,392 \\
\hline T6 & 7,740 & T11 & 6,574 & 1,166 \\
\hline
\end{tabular}

A produtividade em colmo, por ocasião da colheita, mostra um crescimento acompanhando os tratamentos com maiores das doses de vinhaça, complementada ou não com $\mathrm{KCl}$. Elas afetaram positivamente, embora o tratamento que mais recebeu vinhaça produziu menos colmos que aquele que recebeu a adubação mineral preconizada. Esse fato não acompanhando o mesmo comportamento para fibra, que para maiores doses de vinhaça apresentaram menores valores que os tratamentos que só receberam adubação mineral.

A comparação das linhas de tendência apresentadas no gráfico da figura 11, mostra uma tendência acentuada de aumento no número de colmos. ha-1 para os tratamentos que receberam complementação com $\mathrm{KCl}$. 


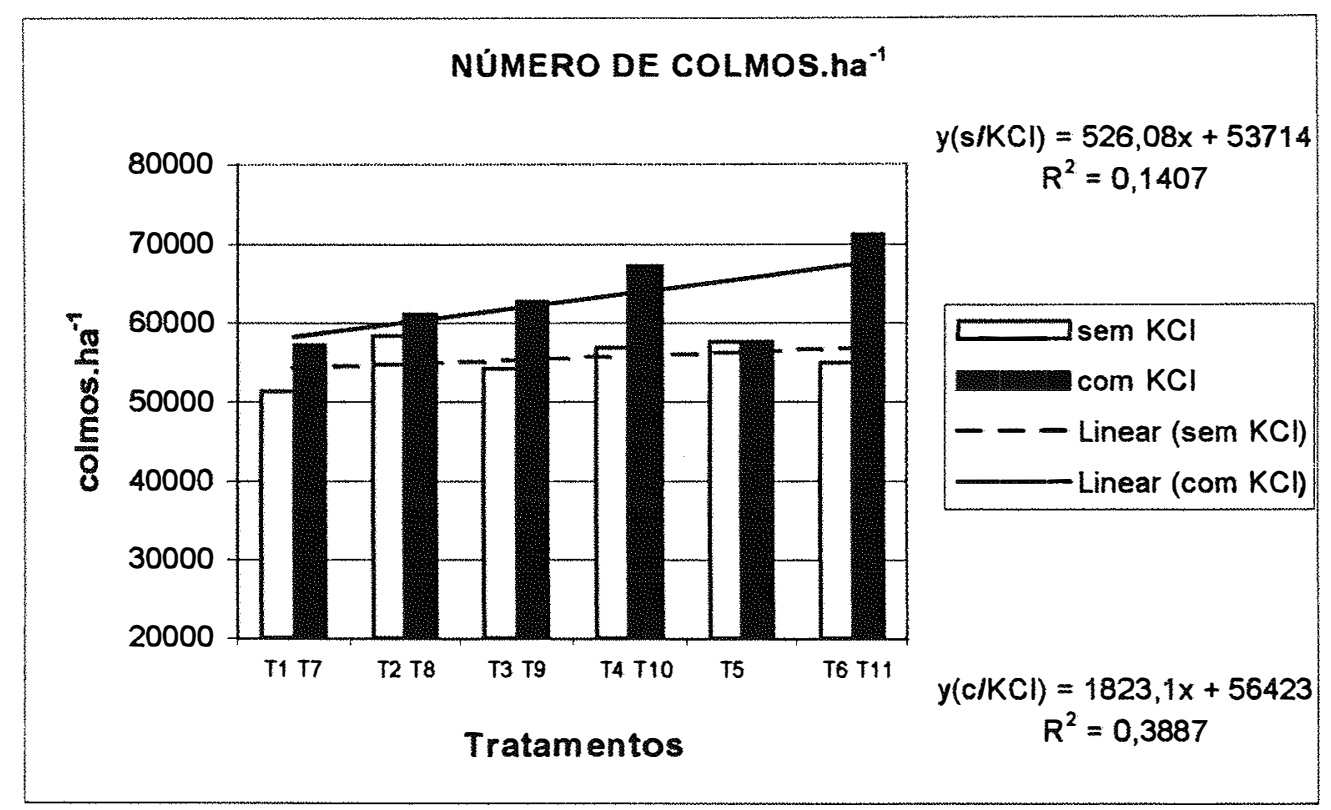

Figura 11: Comparação das médias de número de colmos.ha ${ }^{-1}$, para o mês de outubro, apresentando as linhas de tendência e suas equações ajustadas

As figuras 12 e 13, mostram não haver nenhuma diferença entre os tratamentos que receberam ou não complementação com $\mathrm{KCl}$, em termos de massa de cana-de-açúcar inteira e industrializável (despontada), mas uma linha de tendência de crescimento linear. 


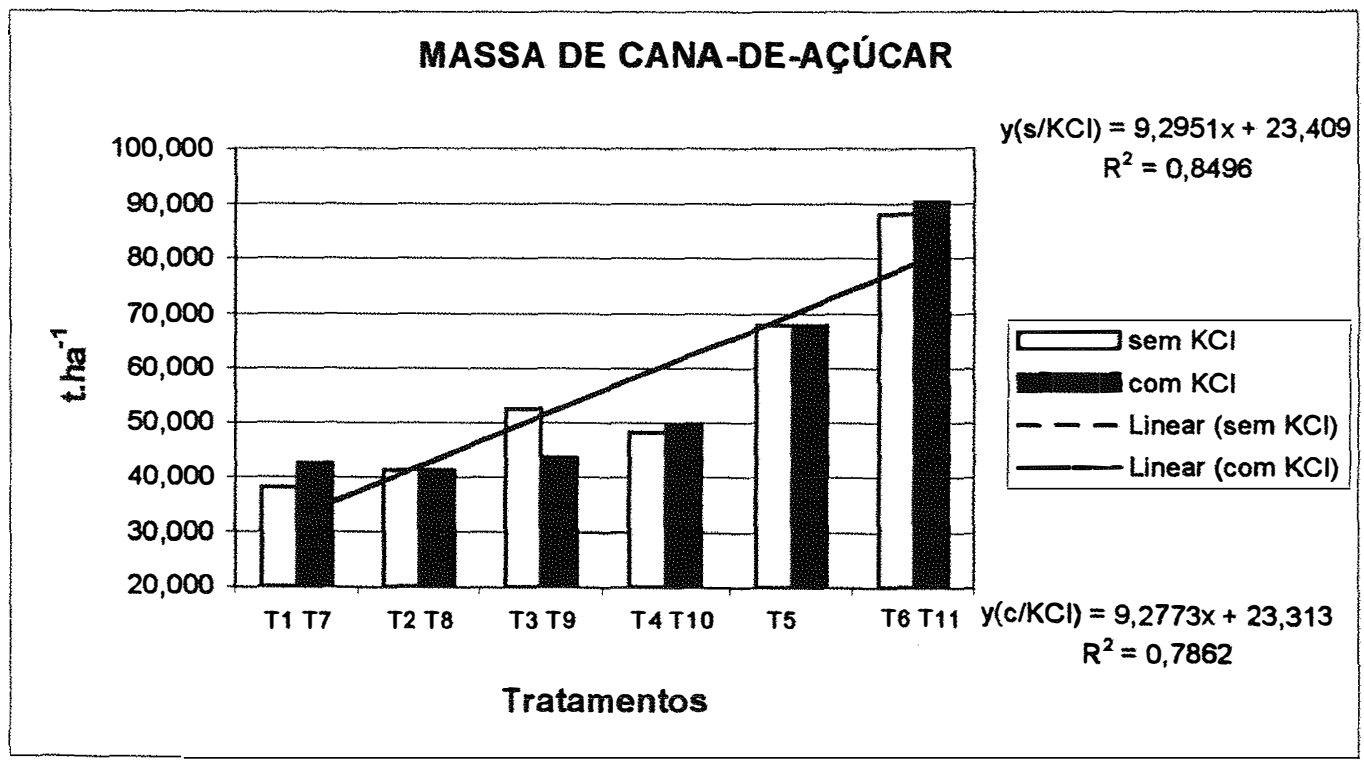

Figura 12: Comparação das médias de massa de cana-de-açúcar.ha ${ }^{-1}$, para o mês de outubro, apresentando as linhas de tendência e suas equações ajustadas

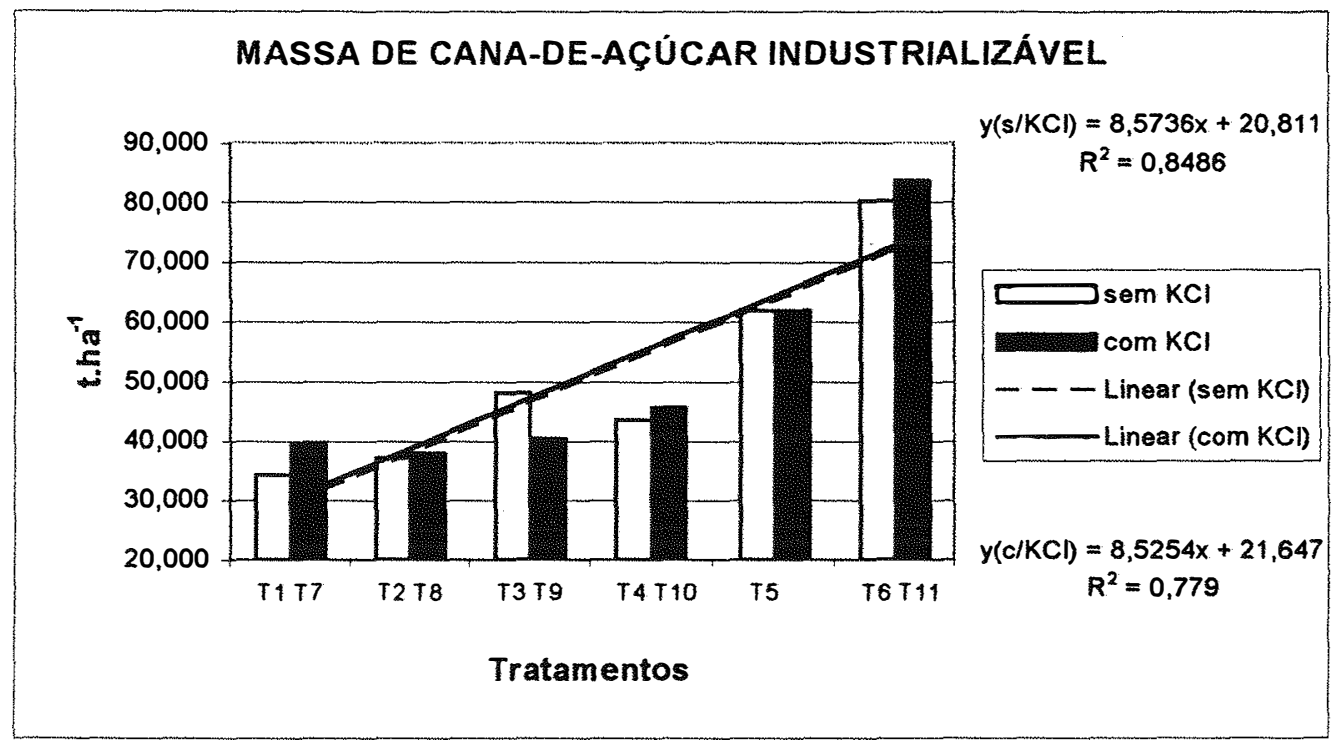

Figura 13: Comparação das médias de massa de cana-de-açúcar industrializável.ha ${ }^{-1}$, para o mês de outubro, apresentando as linhas de tendência e suas equações ajustadas 


\subsection{Açúcar.ha-1}

Ao considerar-se a quantidade de açúcar total recuperável por tonelada de cana, doses elevadas (300 e $400 \mathrm{~m}^{3} \cdot \mathrm{ha}^{-1}$ ) de vinhaça não prejudicam valores de ATR frente à testemunha absoluta e estão pouco abaixo da adubação mineral preconizada. Entretanto, a combinação de vinhaça $+\mathrm{KCl}$ resultou em valores menores do que os tratamentos que receberam só vinhaça. Esse comportamento foi observado para todas as épocas amostradas. $\mathrm{Na}$ produção de açúcar.ha ${ }^{-1}$ calculada em função da ART e da produtividade agrícola de cana despontada, encontra-se que o tratamento de melhor resposta é o da adubação mineral recomendada, com $9.809 \mathrm{~kg}$.ha ${ }^{-1}$ de açúcar, 137,27\% maior que a testemunha absoluta, que apresentou produção de $4.134 \mathrm{~kg} \cdot \mathrm{ha}^{-1}$ de açúcar, e 65,92 \% superior ao tratamento que mais recebeu vinhaça (T4), cuja produção foi de $7.084 \mathrm{~kg}$. ha-1 de açúcar, embora este tenha sido $67,45 \%$ maior que a testemunha absoluta, conforme a tabela 20 , seguindo tendência de trabalho de Silva et al. (1977)

Tabela 20: Produtividade de açúcar $\left(\mathrm{kg}_{\mathrm{h}} \mathrm{ha}^{-1}\right)$

\begin{tabular}{|c|c|c|c|}
\hline Tratamento & $\mathrm{kg} \mathrm{aç.ha}^{-1}$ & Tratamento & ${\mathrm{kg} \mathrm{aç.} . \mathrm{ha}^{-1}}^{-1}$ \\
\hline $\mathrm{T} 1$ & 4134 & $\mathrm{~T} 7$ & 4373 \\
\hline $\mathrm{T} 2$ & 4200 & $\mathrm{~T} 8$ & 4085 \\
\hline $\mathrm{T} 3$ & 5608 & $\mathrm{~T} 9$ & 4466 \\
\hline $\mathrm{T} 4$ & 5258 & $\mathrm{~T} 10$ & 5054 \\
\hline $\mathrm{T} 5$ & 7084 & $\mathrm{~T} 5$ & 7084 \\
\hline $\mathrm{T} 6$ & 9809 & $\mathrm{~T} 11$ & 9786 \\
\hline
\end{tabular}


Da comparação dos tratamentos com e sem complementação com $\mathrm{KCl}$, observa-se um paralelismo entre elas, com ligeira diferença para menor nos tratamentos complementados com KCl, conforme a figura 14.



Figura 14: Comparação das médias de produtividade de açúcar, para o mês de outubro, apresentando as linhas de tendência e suas equações ajustadas

\subsection{0 $\mathrm{K}_{2} \mathrm{O} \times$ Cinzas}

$\mathrm{O}$ aumento nos teores de $\mathrm{K}_{2} \mathrm{O}$ via vinhaça foram acompanhados por um aumento dos teores de cinzas no caldo. Comparando os mesmos teores de potássio no caldo nos tratamentos que mais receberam tal elemento, nota-se que a aplicação de vinhaça resultou em máxima quantidade de cinzas do que a mesma quantidade de potássio via $\mathrm{KCl}$, sendo o mesmo comportamento mostrado para $\mathrm{K}_{2} \mathrm{O}$ no caldo. Os menores teores de cinzas e $\mathrm{K}_{2} \mathrm{O}$ no caldo foram encontrados nos tratamentos que receberam apenas 
adubação mineral, mesmo com a máxima dosagem de $\mathrm{KCl}$, equivalente à máxima dosagem de vinhaça (figura 15). Tal fato pode ser entendido a vinhaça leva o nutriente já solubilizado, prontamente absorvido pela planta, numa absorção de luxo, carreando-o para o caldo, enquanto que o $\mathrm{KCl}$ é absorvido mais lentamente ao longo do desenvolvimento da planta, sendo o $\mathrm{K}_{2} \mathrm{O}$ aproveitado no metabolismo da planta nos muitos estágios da síntese e translocação de açúcares, o que favoreceria o maior desenvolvimento vegetativo e maior produtividade de sacarose, embora a recuperação de açúcar não tenha sido afetada pela adição de $\mathrm{K}_{2} \mathrm{O}$, via vinhaça ou $\mathrm{KCl}$.

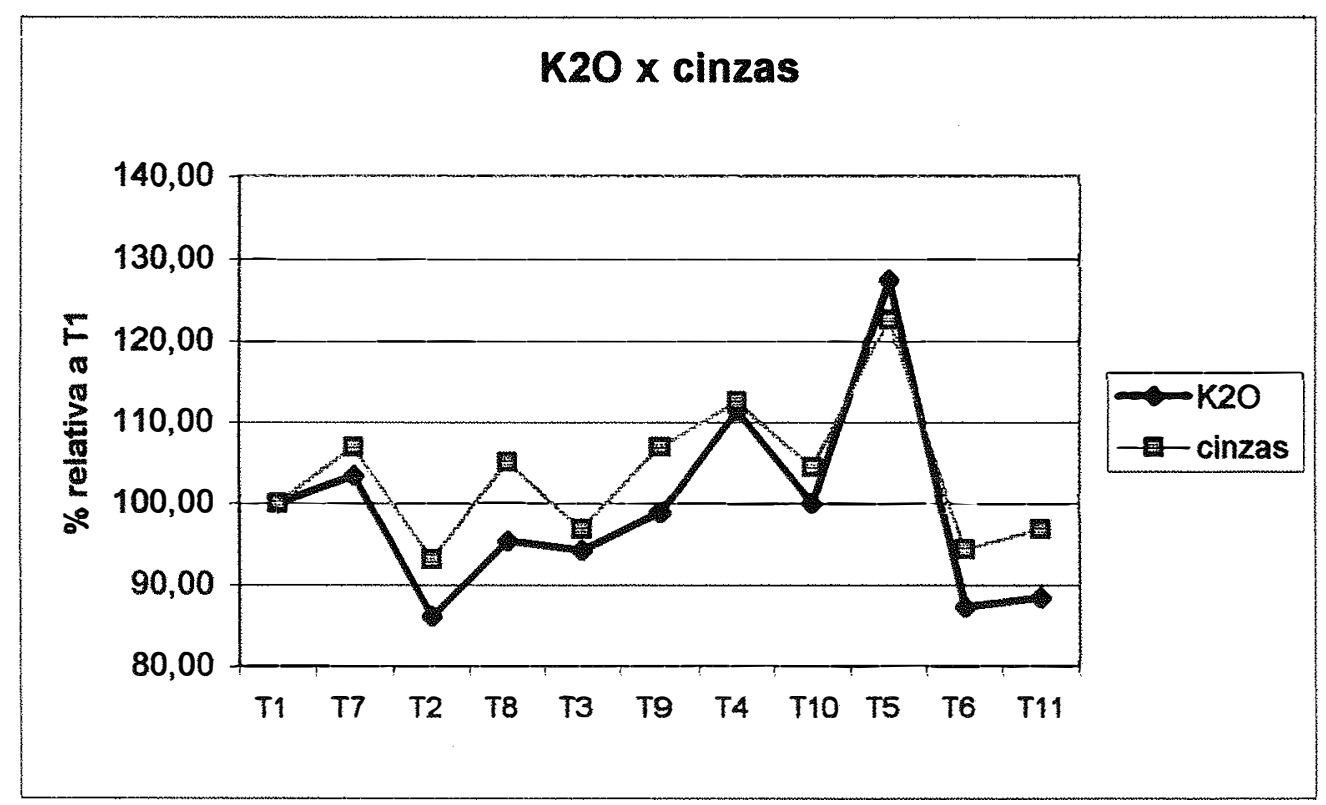

Figura 15: Comparação dos teores de $\mathrm{K}_{2} \mathrm{O}$ e cinzas no caldo, em referência à testemunha absoluta (T1) 


\section{$4.11 \mathrm{~K}_{2} \mathrm{O} \times \mathrm{AR}$}

Os tratamentos que receberam vinhaça e foram complementados com $\mathrm{KCl}$ sempre apresentaram menores teores de AR quando comparados com aqueles que não o receberam, sendo que o tratamento mineral, quando complementado com $\mathrm{KCl}$ até a dosagem máxima no experimento, apresentou o menor teor de $A R$, o que sugere que maiores aplicações de $\mathrm{KCl}$ favorecem maior conversão de açúcares redutores em sacarose, ou inibição da atividade da invertase sobre a sacarose, o que é acompanhado pelo maior rendimento em sacarose ( t.cana $^{-1}$ ). A figura 16, apresenta a variação relativa à testemunha (T1) de $A R$ em função de $\mathrm{K}_{2} \mathrm{O}$ no caldo.

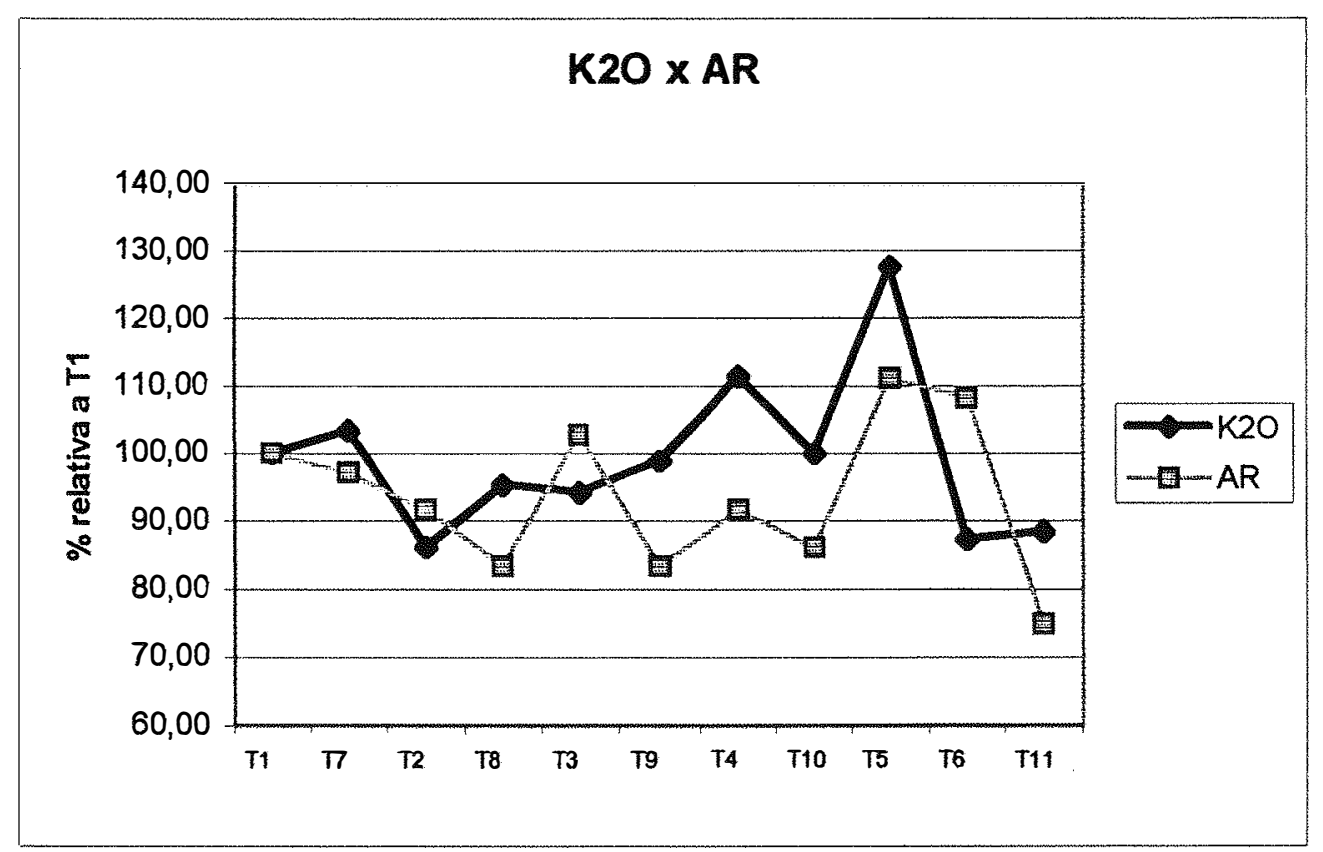

Figura 16: Comparação dos teores de $\mathrm{K}_{2} \mathrm{O}$ no caldo e Açúcares Redutores na cana, em referência à testemunha absoluta (T1) 


\section{$4.12 \mathrm{~K}_{2} \mathrm{O} \times$ desponte e produtividade de colmos}

A partir dos resultados obtidos, e estabelecida uma comparação entre teores de $\mathrm{K}_{2} \mathrm{O}$ no caldo com a produtividade de colmos e da massa despontada, não é possível estabelecer uma correlação entre eles, pois o maior teor de $\mathrm{K}_{2} \mathrm{O}$ no caldo apresenta uma das mais altas produtividade em colmos e médio desponte, enquanto que os menores teores de $\mathrm{K}_{2} \mathrm{O}$ no caldo estão relacionados também com maiores produtividade em colmos e baixos a médios desponte (figura 17).

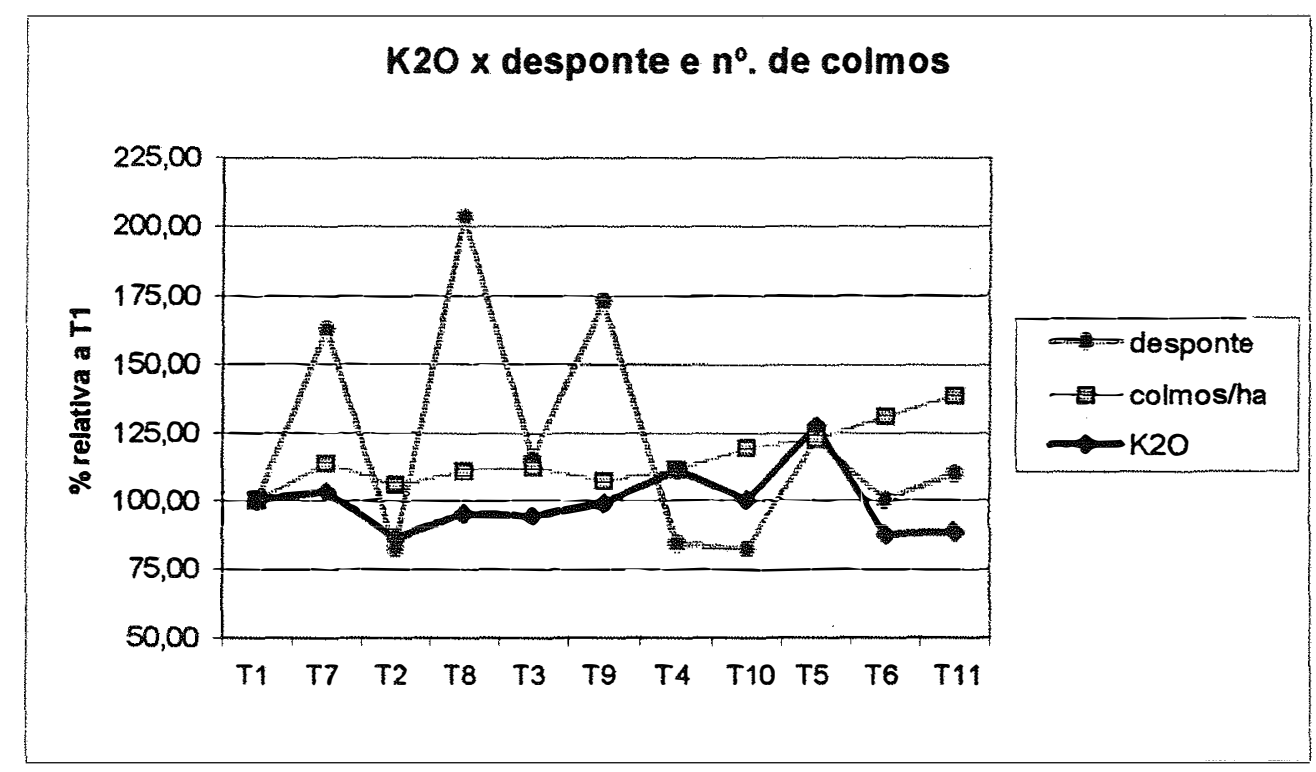

Figura 17: Comparação dos teores de $\mathrm{K}_{2} \mathrm{O}$ no caldo, desponte e produtividade de colmos, em referência à testemunha absoluta (T1)

Desta constatação pode-se afirmar que outros fatores influenciam nesses aspectos, além da quantidade do potássio no caldo. Há que ressaltar que os menores teores de $\mathrm{K}_{2} \mathrm{O}$ no caldo são apresentados pelos tratamentos que mais receberam esse elemento no solo via mineral, sem a 
participação da vinhaça, o que mostra a importância de um suprimento balanceado dos elementos na prática da adubação.

\subsection{Fibra x Pureza x Umidade}

Estes fatores da qualidade muito pouco foram afetados pelos tratamentos, ocorrendo um decréscimo nos teores de fibra com o aumento nas dosagens de $\mathrm{K}_{2} \mathrm{O}$, seja via vinhaça como pela adição de $\mathrm{KCl}$ (figura 18). Entretanto, o tratamento que mais recebeu vinhaça, também foi aquele que apresentou maior teor de umidade e menor pureza, o que pode ser entendido pelo decréscimo do potencial osmótico das células em função do acúmulo de $\mathrm{K}^{+}$, determinando maior retenção de água nos tecidos (Malavolta \& Crocomo, 1982).

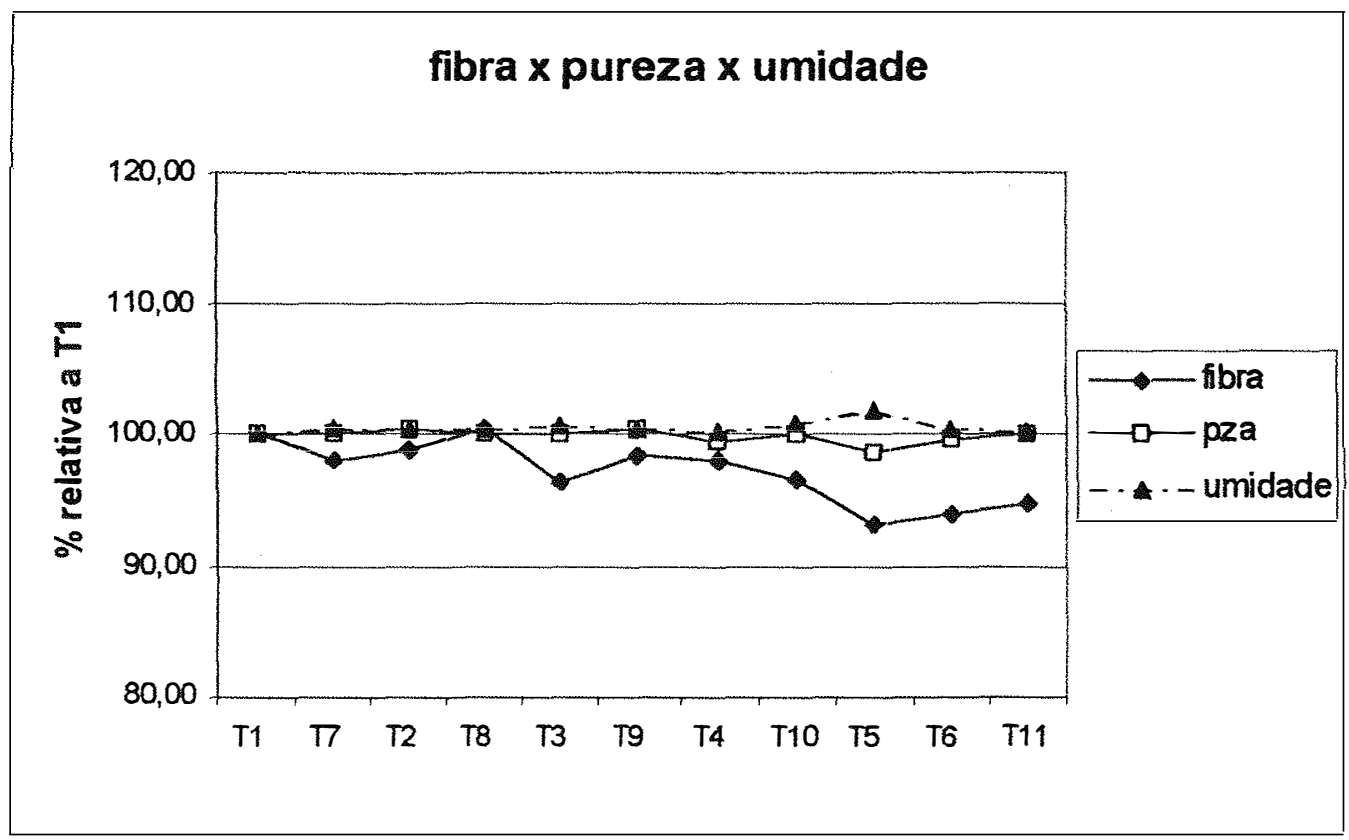

Figura 18: Comparação dos teores Fibra, Pureza e Umidade \% cana em referência à testemunha absoluta (T1) 
Enquanto que para os teores de fibra nada indica que componentes da vinhaça promovam efeito favorável ou desfavorável a eles, concordando com observações de Glória \& Orlando Fo. (1983).

\subsection{4 $\mathrm{K}_{2} \mathrm{O} \times$ Brix e Pol}

Pode-se afirmar que esses fatores da qualidade da cana-deaçúcar não apresentaram importantes variações em função dos tratamentos testados. Vale ressaltar, porém, que a maior quantidade de vinhaça aplicada resultou em efeito depressivo para Brix e Pol, enquanto que os tratamentos que receberam $\mathrm{K}_{2} \mathrm{O}$, somente via $\mathrm{KCl}$, apresentaram efeito positivo, resultando em maiores teores de Brix e Pol observados no experimento, mais uma vez comprovando a superioridade da adição do $\mathrm{K}_{2} \mathrm{O}$ via mineral do que via vinhaça (figura 19).

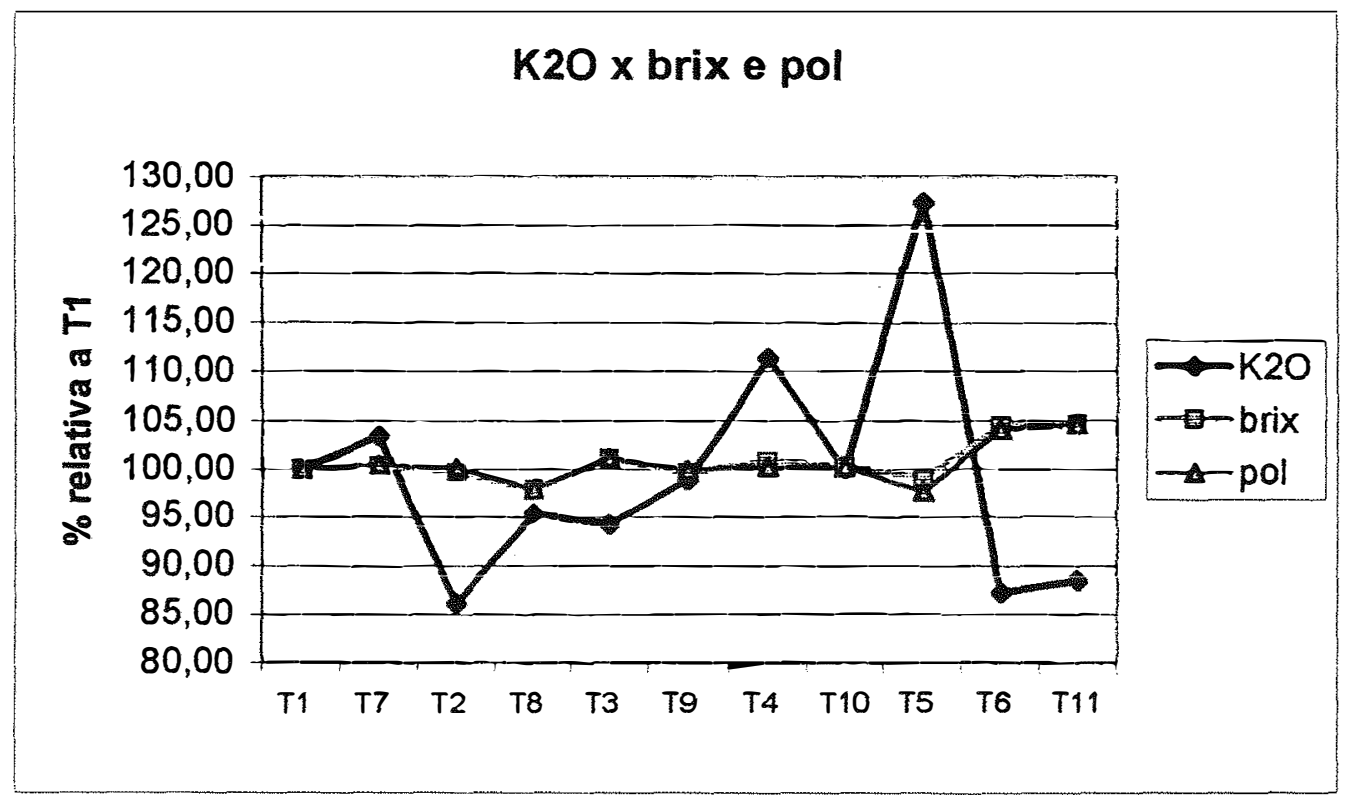

Figura 19: Comparação dos teores $\mathrm{K}_{2} \mathrm{O}$ no caldo, Brix e Pol da cana em referência à testemunha absoluta $(\mathrm{T} 1)$ 


\subsection{Produtividade $\times \mathrm{K}_{2} \mathrm{O}$}

$\mathrm{O}$ fornecimento de $\mathrm{K}_{2} \mathrm{O}$ para a cultura da cana-de-açúcar é essencial, e quando é feito via adubação mineral recomendada produz resultados esperados, portanto, não sendo recomendado aumento na dosagem de $\mathrm{KCl}$, uma vez que não há melhoria na produtividade de açúcar.

O uso de vinhaça, objetivando a total substituição da adubação mineral resulta em incremento na produtividade, tanto em cana como em açúcar, quando comparada com a testemunha, mesmo em solo TE, embora seja insuficiente para produzir os mesmos resultados da adubação mineral preconizada, com o agravante de aumentar significativamente o teor de $\mathrm{K}_{2} \mathrm{O}$ e cinzas no caldo.

Destinando a cana de talhões que receberam vinhaça para a produção de álcool, poderá ser vantagem o emprego da vinhaça frente à adubação mineral em função do custo de aquisição e aplicação do adubo, que inclusive sofre com as questões relativas à importação do $\mathrm{KCl}$, enquanto há a necessidade de descarte adequado do resíduo líquido da destilação, que é a vinhaça.

A figura 20, evidencia a influência de outros fatores, não avaliados neste experimento, na produtividade de cana-de-açúcar e açúcar teórico recuperável, pois menores e maiores teores de $\mathrm{K}_{2} \mathrm{O}$ no caldo correspondem às maiores produtividade, evidenciando a importância do balanceamento nutricional da cana-de-açúcar para maior conversão desses em massa vegetativa e açúcar na planta. 


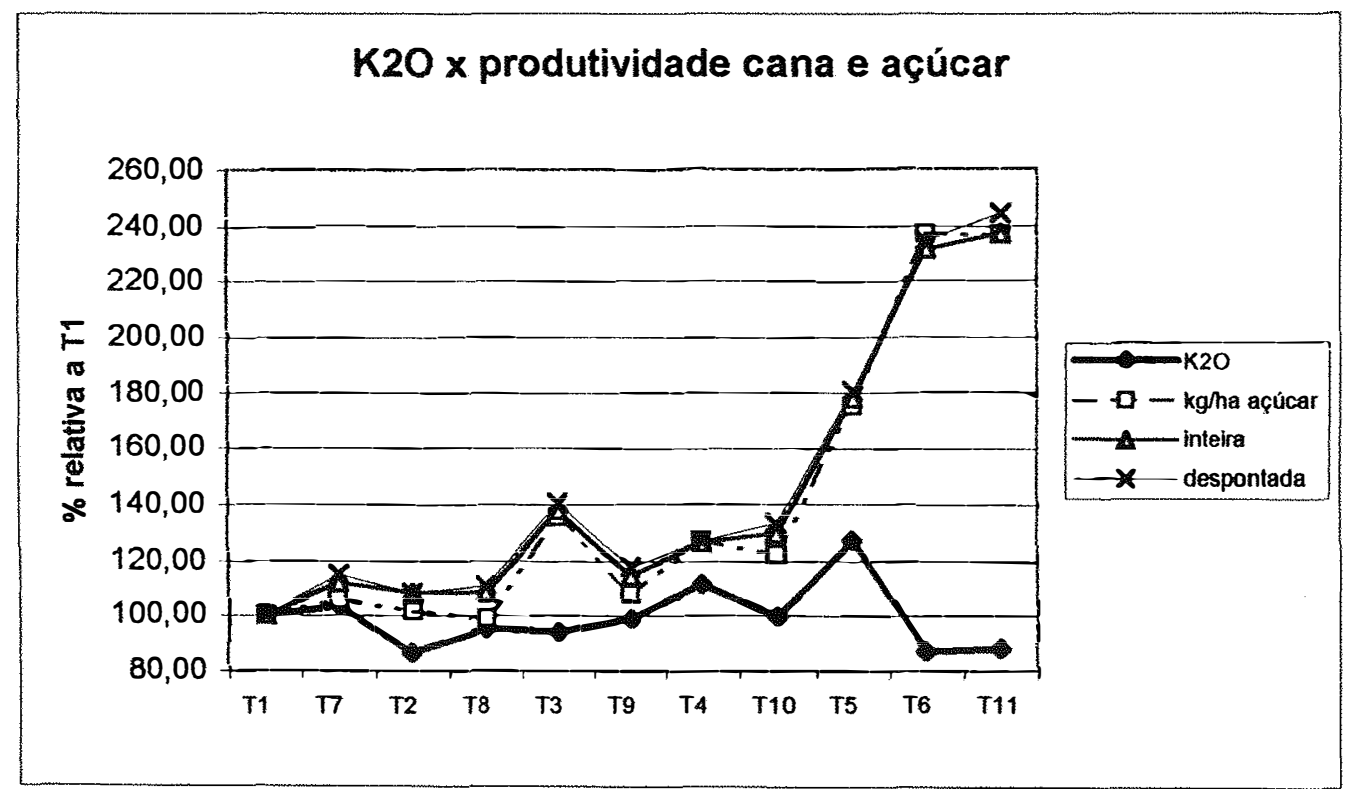

Figura 20: Comparação dos teores $\mathrm{K}_{2} \mathrm{O}$ no caldo, produtividade de cana, cana despontada e de açúcar, em referência à testemunha absoluta (T1)

\subsection{Vinhaça $\times \mathrm{KCl}$}

O comportamento dos tratamentos, em resumo, apresentaramse identicos quando complementados ou não com $\mathrm{KCl}$, até a dosagem máxima de $248 \mathrm{~kg} \mathrm{~K}_{2} \mathrm{O} \cdot \mathrm{ha}^{-1}$, não havendo resposta significativa em função da mesma. Tal fato pode ser entendido em vista de que o potássio é absorvido em excesso pela planta e fica "sobrando" nela, pois não encontra os demais elementos necessários para seu aproveitamento e interação no metabolismo da planta e aparece depois no caldo e nas folhas de onde pode inclusive ser perdido por ação da chuva, como mostra Sampaio \& Salcedo (1991). 


\section{CONCLUSÃO:}

Em função dos resultados obtidos neste experimento, é possivel afirmar que, em relação à testemunha absoluta, os tratamentos que receberam vinhaça apresentaram um incremento em produtividade de cana-deaçúcar e de açúcar , com aumento progressivo nos teores de potássio e cinzas, acompanhando o aumento nas doses de vinhaça aplicada nos tratamentos.

O tratamento que recebeu a adubação mineral preconizada mostrou melhores resultados em produtividade de cana-de-açúcar e de açúcar , e os menores teores de potássio e cinzas, quando comparados aos demais tratamentos, portanto, matéria-prima de melhor qualidade.

Destinando a cana de talhões que receberam vinhaça para a produção de álcool, poderá ser vantagem o emprego da vinhaça frente à adubação mineral em função do custo de aquisição e aplicação do adubo, que inclusive sofre com as questões relativas à importação do $\mathrm{KCl}$, enquanto há a necessidade de descarte adequado do resíduo líquido da destilação, que é a vinhaça.

A complementação com $\mathrm{KCl}$ mostrou-se prejudicial a todos os tratamentos, pois aumentou a massa despontada, sem entretanto aumentar a produtividade de açúcar, elevando os teores de potássio e cinzas no caldo de cana, prejudicando assim a qualidade da matéria-prima. Um estudo incluindo o balanço de potássio pode apontar com clareza a destinação desse elemento aplicado via adubação mineral ou através da vinhaça e seus efeitos na planta. 


\section{APÊNDICE}

Tabela 6. Resultados de Análises da Vinhaça utilizada no experimento

\begin{tabular}{|c|c|c|c|}
\hline ELEMENTO & $g \cdot L^{-1}$ & ELEMENTO & $g \cdot L^{-1}$ \\
\hline Resíduo seco a $100-110^{\circ} \mathrm{C}$ & 8,98 & Potássio $\left(\mathrm{K}_{2} \mathrm{O}\right)$ & 0.62 \\
\hline Matéria orgânica total ( combustão ) & 7,13 & Cálcio (Ca) & 0.11 \\
\hline Carbono total (orgânico e mineral) & 3,96 & Magnésio (Mg) & 0.15 \\
\hline Resíduo mineral total & 1,85 & Enxofre (S) & 0.19 \\
\hline Resíduo mineral insolúvel & 0,07 & & \\
\hline Resíduo mineral solúvel & 1,78 & Índice pH & $3.20^{*}$ \\
\hline Nitrogênio total & 0,21 & Relação C/N (C total e $N$ total) & $19 / 1$ * \\
\hline Fósforo $\left(\mathrm{P}_{2} \mathrm{O}_{5}\right)$ total & 0,12 & & \\
\hline
\end{tabular}

* Valor absoluto 
Tabela 7: Resultados de Análise de Solo ${ }^{\#}$ (TE) da área do experimento

\begin{tabular}{|c|c|c|c|}
\hline ELEMENTO & & ELEMENTO & \\
\hline Saturação de bases & $65.50 \%$ & Cálcio & $44,0 \mathrm{mmol}_{\mathrm{c}} \cdot \mathrm{dm}^{-3}$ \\
\hline Soma de bases & $59,10 \mathrm{mmol}_{\mathrm{c}} \cdot \mathrm{dm}^{-3}$ & Magnésio & $13,0 \mathrm{mmol}_{\mathrm{c}} \cdot \mathrm{dm}^{-3}$ \\
\hline стс & $90,1 \mathrm{mmol}_{\mathrm{c}} \cdot \mathrm{dm}^{-3}$ & $\mathrm{pH}(\mathrm{CaCl})$ & 5.30 \\
\hline Matéria Orgânica & $4,9 \mathrm{~g} \cdot \mathrm{dm}^{-3}$ & $\mathrm{pH}(\mathrm{SMP})$ & 6.30 \\
\hline Alumínio & & Fósforo & $13.00 \mathrm{mg} \cdot \mathrm{dm}^{-3}$ \\
\hline$H+A l$ & $31,0 \mathrm{mmol}_{\mathrm{c}} \cdot \mathrm{dm}^{-3}$ & Potássio & $\begin{array}{c}2,1 \mathrm{mmol}_{\mathrm{c}} \cdot \mathrm{dm}^{-3}= \\
\left(84 \mathrm{mg} \cdot \mathrm{dm}^{-3}\right)\end{array}$ \\
\hline
\end{tabular}

\# Método utilizado para extração de potássio foi do ácido sulfúrico 0,5 N. 


\section{BIBLIOGRAFIA CONSULTADA}

AGRIANUAL/99 - Anuário da Agricultura Brasileira. FNP - Consultoria \& Comércio. 1999 p. 232-233.

AGUJARO, R. O Uso da Vinhaça na Usina Tamoio como Fertilizante. Saccharum, v.2, n.4, p. 23-27, mar. 1979.

ALEXANDER, A.G. Sugarcane Physiology: a compreehensive study of the Saccharum source-to-sink system. Amsterdam, Elsevier. 752 p. 1973.

ALMEIDA, J.R. O Problema da Vinhaça em São Paulo. Boletim do Instituto Zimotécnico. n.3, p.1 - 24. 1952.

ALMEIDA, J.R. de. Composição, proporção e aplicação da vinhaça. In: III SEMANA DE FERMENTAÇÃO ALCOÓLICA, Piracicaba. Instituto Zimotécnico. V.2, p. 370-383. 1962.

ALVES, M.C. Vinhoto: Fonte Alternativa de Biomassa Forrageira. STAB, v.5, n.3, p. 43 - 48, jan/fev. 1987.

ALVES, M.C.; ORLANDO Fo. J.; BITTENCOURT V.C. Aplicação de Vinhaça em Solo Arenoso no Brasil e Poluição do Lençol Freático com Nitrogênio. STAB, v.13, n.6, p.14 - 16, jul/ago. 1995.

AZEREDO, D.F. ; MANHÃES, M.S. Efeitos da aplicação de vinhaça em cana-soca no Estado do Rio de Janeiro. In: CONGRESSO NACIONAL DA SOCIEDADE DOS TÉCNICOS AÇÚCAREIROS DO BRASIL, V. 1 Maceió, 1979.

AZEREDO, D.F.; ROBAINA, A.A.; LAVORENTI, N.A. Correlação entre algumas características do solo e resposta da cana-soca à aplicação de vinhaça. In: III CONGRESSO NACIONAL DA SOCIEDADE DOS TÉCNICOS AÇÚCAREIROS E ALCOOLEIROS DO BRASIL - STAB. Anais. São Paulo, 19 - 24 de agosto de 1984, p.36 - 39. 
BAPTISTELLA, J.R. , LEME, E.J.A. , ROSENFELD, U. "Estudo de doses de vinhaça aplicada por aspersão em cana-de-açúcar". IN II CONGRESSO NACIONAL DA SOCIEDADE DE TÉCNICOS AÇUCAREIROS DO BRASIL. Anais. Rio de Janeiro 16-21 agosto 1981. Vol I. p. 215-234.

BOLSANELLO, J \& VIEIRA, J.R. Caracterização da composição química dos diferentes tipos de vinhaça da região de Campos-RJ. Brasil Açúcareiro, Rio de Janeiro, vol.96, n.5, p. 45-59, nov.1980

BROWNE, C.A.; ZERBAN, F.W. - Physical and Chemical Methods of Sugar Analysis. 3rd. ed.New York, Wiley, 1941. 135 p.

CAMBUIM F.A.; CORDEIRO D.A. Ação da Vinhaça sobre pH , Acidez total , Acumulação e Lixiviação de Nutrientes em Solo Arenoso. STAB n.4, v.4, p. 27 - 33, mar/abr. 1986.

CESAR, M.A.A. ; SILVA, F.C. da. A cana-de-açúcar como matériaprima para a indústria sucroalcooleira. Piracicaba, CALQ, 1993. $107 p$.

COELHO M.B.; AZEVEDO H.J. Utilização da Vinhaça na Irrigação da Cana-de-açúcar. STAB n.5, v.4, p. 49 - 52, mailjun. 1986.

COLETI, J.T. Fertilização com vinhaça da Usina Santa Adelaide. Brasil Açúcareiro, Rio de Janeiro, v. 92, n.5, p. 38-50, nov. 1978.

COLETI J.T.; LORENZETTI, J.M.; GASPARINI, C.T.; DEMATTÉ, J.L.I. \& FREITAS P.G.R. Efeito da Aplicação da Vinhaça nas Propriedades dos Solos da Usina São José - Macatuba. STAB v.1, n.3, p. 12 - 17, jan/fev. 1983.

COLETTI, J.T. Fertilização com Vinhaça da Usina Santa Adelaide. Brasil Açúcareiro, v.92, n.5, p.38-50, nov.1978

COPERSUCAR - Divisão de Estudos e Pesquisas e Divisão Agronômica. "Efeitos da aplicação de vinhaça como fertilizante em cana-de-açúcar". Boletim Técnico Copersucar, n. 7 p. 9-14 nov. 1978.

COPERSUCAR. "Aplicação de vinhaça à soqueira de cana-de-açúcar em 3 anos consecutivos" Boletim Técnico Copersucar, n.12, p. 2-5, jun. 1980. 
CRAVEIRO, A.M. A Biodigestão do Vinhoto nas Destilarias de Álcool Aspectos Técnicos e Econômicos. In: SEMINÁRIO DE AVALIAÇÃO DO VINHOTO DAS DESTILARIAS DE ÁLCOOL COMO COMBUSTIVEL EM SUBSTITUIÇÃO AO ÓLEO DIESEL E OUTROS USOS. São Paulo, 1985. Anais. Avaliação do Vinhoto como Substituto do Óleo Diesel e outros Usos. São Paulo: SOPRAL, p 516, 1986.

FERREIRA, E.S. ; MONTEIRO A.D. "Efeitos da Aplicação da Vinhaça nas propriedades Químicas, Físicas e Biológicas do Solo". Boletim Técnico Copersucar, n.36 p. 3-7, jan.1987

FURLAN, No.,V.L.; MAGRO J.A.; SALAGATO S.L.; ROSENFELD, U.;STOLF R.; LUZ P.H.C. Formas de Cultivo da Cana-soca. Associação à Utilização Agrícola da Vinhaça como Adubação Mineral. STAB, v.3, n.6, p.46-52. jul/ago. 1985.

GERMEK H.A.; FEIGL G.F. Processos de Redução de Vinhaça. STAB.v.5, n.4, p.42-50, marlabr. 1987.

GLÓRIA, N.A. ; MAGRO, J.A. Utilização Agrícola de Resíduo da Usina de Açúcar e Destilaria na Usina da Pedra. In: IV SEMINÁRIO DA COPERSUCAR DA AGROINDÚSTRIA AÇÚCAREIRA, Águas de Lindóia, 1976. Anais. Águas de Lindóia: COPERSUCAR, 1976. p.163-180.

GLÓRIA N.A.; MATTIAZZO, M.E. Efeito da Matéria Orgânica na solubilização de Fosfatos no Solo II. Efeito de resíduos de Usinas de Açúcar e Destilarias (bagaço de cana, torta de filtro e vinhaça). Brasil Açucareiro, v.88, n.5, p.386-395, nov.1976.

GLÓRIA N.A. ; ORLANDO, Fo.J. Aplicação da Vinhaça como Fertilizante. Boletim Técnico PLANALSUCAR, v.5, n.1, 1983.

GLÓRIA, N.A. Efeito do Potássio na Acumulação de Sacarose pela Canade-Açúcar. Álcool e Açúcar, v.5, n. 23 , p. 20 -25, jul/ago 1985.

GOMES, P.F. A lei de Mitscherlich aplicada a experimentação de adubação com vinhaça. Anais da ESALQ. Piracicaba, n. 14, p. 107112, 1957.

GOMES, P. F. Curso de estatística experimental. São Paulo. Nobel, 1985. $466 \mathrm{p}$. 
GUTIERREZ, L.E; FERRARI, S.E.; GERALD L.T.S.; ORELLI Jr. A.A. Efeito da aplicação de vinhaça como fertilizante sobre os teores de ácido trans-aconítico de caldo de cana-de-açúcar (Saccharum, sp). In: Anais da Escola Superior de Agricultura "Luiz de Queiroz". V. 45, n. 2, p. 453-462. 1988.

LANE, J.H.; EYNON, L. - Determination of Reducing Sugars by Fehling"s Solution with Methylene Blue Indicator. London, Norman Rodger, 1934. 8p.

LEME, E.J.A.; ROSENFELD, U.; BATISTELA, J.R. Aplicação da Vinhaça em Cana-de-açúcar por Aspersão. Boletim Técnico PLANALSUCAR, série $B$, v.1, n.4, p.3-42, 1979.

LORENZETTI, J.M.; FREITAS, P.G.R. Aplicação da Vinhaça por Aspersão. Saccharum. v.1, n.2, p.16 -22, set.1978.

MALAVOLTA, E ; CROCOMO, O. J. O potássio e a planta. In: SIMPÓSIO SOBRE POTÁSSIO NA AGRICULTURA BRASILEIRA, Londrina, 2528 de janeiro de 1982. Anais Piracicaba. Instituto da Potassa \& Fosfato (EUA) e Instituto Internacional da Potassa (Suiça), 1982. p.95162.

MARINHO, M.L.; ALBUQUERQUE, E.A.C.; ARAÚJO Fo. J.T. Efeitos de doses de vinhaça e adubação mineral sobre a cana-soca em dois solos de Alagoas. Brasil Açúcareiro. V.99, n.2, p. 39-50, fev. 1982.

MATTIAZZO, M.E.; GLÓRIA N.A. Efeito da Vinhaça na Acidez do Solo. STAB,v.4, n.2, p 35-40, nov/dez. 1985.

MEDEIROS, A.P. Composição química dos diferentes tipos de vinhaça nos Estados de Pernambuco, Paraíba e Rio Grande do Norte. Saccharum STAB, São Paulo, vol. 4 n. 12 p. 36-40, jan. 1981.

MOLINA, P.C.; LEME, E.J.A.; ROSENFELD, U.; BATISTELLA, J.R. Efeito de soses crescentes de vinhaça aplicada por aspersão na produtividade da cana-de-açúcar. In: III CONGRESSO NACIONAL DA SOCIEDADE DOS TÉCNICOS AÇÚCAREIROS E ALCOOLEIROS DO BRASIL - STAB. Anais. São Paulo, 19 - 24 de agosto de 1984, p. 27 30.

NUNES, D. Jr. "Efeitos da elevada deposição de vinhaça sobre variedades de cana-de-açúcar". Boletim Técnico Copersucar .vol. 37 p. 38-44 maio 1987

ORLANDO $\mathrm{F}^{\circ}$, J. Nutrição e Adubação da Cana-de-açúcar no Brasil. Coleção PLANALSUCAR, n. 2, Piracicaba: IAA 1983. 369 p. 
ORLANDO Fo. J.; BOARETTO, A.E.; GLÓRIA, N.A. Adubação Potássica em Cana-de-açúcar: I - Efeitos na Produtividade Agrícola, Qualidade da Matéria-prima e Longevidade. STAB. v. 12, n. 1, set/out. 1993

ORLANDO Fo.,J. ; SOUSA, I.C. ;ZAMBELLO Jr.,E. Aplicação de Vinhaça em Soqueiras de Cana de Açúcar. Boletim Técnico PLANALSUCAR, v.2, n.5, p.5-35, set.1980.

ORLANDO $\mathrm{F}^{\circ} ., \mathrm{J}$; ; ZAMBELLO Jr., E.; AGUJARO R.; ROSSETTO J.A. Efeito da Aplicação Prolongada da Vinhaça nas Propriedades Químicas dos Solos em Cana-de-açúcar - Estudo Exploratório. STAB. v. 1, n. 6, p. 28-23, jul/ago 1983 .

PARAZZI, C.; GLÓRIA,N.A.; MATTIAZZO M.E.; PEREIRA, V.; CORREA, L.J.J. Efeitos da Vinhaça nas propriedades Químicas dos Solo e Composição da Cana-de-açúcar. In: III CONGRESSO NACIONAL DA STAB e V CONVENÇÃO DA ACTALAC. São Paulo,1984. Anais do III Congresso Nacional da STAB, e V Convenção da ACTALAC, São Paulo: STAB, 1984, p 39 - 48.

PEIXOTO M.J.C. ; COELHO M.B. "Aplicação de vinhaça diluida em canade-açúcar por sistema de aspersão". In: II CONGRESSO NACIONAL DA SOCIEDADE DE TÉCNICOS AÇÚCAREIROS DO BRASIL. Anais. Rio de Janeiro 16-21 agosto 1981. Vol. I p. 177-194.

PENATTI, CP. , CAMBRIA, S., BONI, P.S., ARRUDA, F.C., MANOEL, L.A. "Efeitos da aplicação de vinhaça e nitrogênio na soqueira de cana-deaçúcar". Boletim Técnico Copersucar n .44 out. 1988 p. 32-38.

ROBAINA A.A.; VIEIRA J.R.; AZEREDO, D.F.; BOLSANELLO, J.; MAGALHÃES M.S. Doses e Complementação Mineral da Vinhaça em Socas de Cana-de-açúcar. Brasil Açucareiro, v. 102 n. 1 p. 26-33, jan/fev. 1984.

ROCHA, B.B.M. Vinhaça: Tratamento por Biodigestão Anaeróbia. Perspectivas Atuais. STAB, v. 7, n. 1, p. 49 - 54 , set/out 1988.

RODELLA, A.A.; FERRARI, S.E. A Composição da Vinhaça e Efeitos de sua Aplicação como Fertilizante na Cana-de-açúcar. Brasil Açúcareiro, v.90, n.7, p.6-13, jul.1977.

RODELLA, A.A.; PARAZZI, C.; CARDOSO, A.C. Composição de Vinhaça de Destilarias Autônomas. Brasil Açúcareiro, v.96, n.4, p. 25 - 28, out.1980. 
ROSENFELD, U.; BAPTISTELLA J.R. \& LEME E.J.A. "Aplicação de Vinhaça por Aspersão em Latossolo Roxo". In: II CONGRESSO NACIONAL DA SOCIEDADE DE TÉCNICOS AÇUCAREIROS DO BRASIL. Anais. Rio de Janeiro 16-21 agosto 1981. Vol. I, p.235-248 .

ROSSETTO, A. J. ; RESENDE, L.C.L.; ALONSO, J.C.; BUSSIOLI Fo.,S.; MARGUERON, L.N. ; SILVA, J.A.; MILLER, L.C. Sistemas de distribuição de vinhaça utilizados pela Usina São João, Araras-SP. In: I SEMINÁRIO SOBRE VINHAÇA, COMPOSIÇÃO E APLICAÇÃO. Anais. Piracicaba, p. 10-38. 1977.

SAMPAIO,E.V.S.B \& SALCEDO, I.H. "Donâmica de nutrientes em canade-açúcar. V. Balanço de K em quatro ciclos de cultivo". Pesquisa Agropecuária Brasileira v. 26, n.9 p. 1323 - 1335, set. 1991.

SCHNEIDER, F. Sugar analysis methods. Peterborough. ICUMSA, 1979. 256p.

SILVA, G.M.A. \& GURGEL M.N.A. "Aplicação de vinhaça como fertilizante em cana-de-açúcar em solo LE, fase arenosa". In: II CONGRESSO NACIONAL DA SOCIEDADE DE TÉCNICOS AÇÚCAREIROS DO BRASIL. Anais. Rio de Janeiro 16-21 agosto1981. v. I p. 140-152.

SILVA, G, M. DE A. Efeitos da aplicação de vinhaça no estado nutricional , produtividade e qualidade tecnológica da cana-de-açúcar (Saccharum spp) em dois tipos de solo. Piracicaba, 1982. 121 p. Dissertação ( Mestrado ) - Escola Superior de Agricultura "Luiz de Queiróz", Universidade de São Paulo.

SILVA, G.M. DE A., CASTRO, L.J.P. DE; MAGRO, J.A. Comportamento agroindustrial da cana-de-açúcar em solo irrigado com vinhaça. In : IV SEMINÁRIO DA COPERSUCAR DA AGROINDÚSTRIA AÇÚCAREIRA, Águas de Lindóia, 1976. Anais. Águas de Lindóia: COPERSUCAR, 1976. p. 107-122.

SILVA, G.M.A.; ORLANDO Fo., J. Caracterização da Composição Química dos Diferentes Tipos de Vinhaça no Brasil. Boletim Técnico PLANALSUCAR, v.3, n.8, p. 5-22 ago.1981.

SILVA L.C.F.; ZAMBELLO $F^{\circ}$.,E.; ORLANDO Fo. J.; ARRUDA Fo..H.C. Utilização da Vinhaça Seca e das Cinzas de Caldeira como Fertilizantes na Cultura da Cana-de-açúcar. STAB,v.1, n.6, p. 35 - 41, jul/ago. 1983. 
SOBRAL, A.F., CORDEIRO, D.A. E SANTOS M.A.C. Efeitos da Aplicação de vinhaça em socarias de cana-de-açúcar. Brasil Açúcareiro, v. 98 n. 5. p. 52-58 nov. 1981.

SPENCER, G.L.; MEADE, G.P. - Manual de Fabricantes de Azúcar de Caña y Químicos Azucareros. Traduzido por G.L. Bourbakis. $7^{\mathrm{a}}$. ed. New York, Wiley, 1932. 624p.

SRUR A.U.O.S; AQUARONE, E. Depuração da Vinhaça pela Produção de Biomassa de Rhodotorula gracilis. STAB,v.2, n.1, p. 34 - 37, set/out. 1983.

STUPIELLO, J.P., PEXE, C.A., MONTEIRO, H.; SILVA, L.H. Efeitos da aplicação da vinhaça como fertilizante na qualidade da cana-deaçúcar. Brasil Açúcareiro. v. 90, n.3 p. 41-49, set.1977.

STURION, A.C. \& FERNANDES, A.C. Análise direta da cana-de-açúcar pelo método para prensa hidráulica. Boletim Técnico COPERSUCAR, v.8, p.12-15, 1979.

TANIMOTO, T. The press method of cane analysis, Hawaii, Pers'Rec, v. 51, n. 2, p. $133-150,1964$

USINEIRO. Novas Variedades RB para a região Centro-Sul do Brasil. Usineiro, v. 3, n. 13, p.6-20, mai./jun. 1988.

VASCONCELOS, J. N. ; OLIVEIRA, C.G. Composição química dos diferentes tipos de vinhaça das destilarias de álcool de Alagoas Safra 1978/79. Saccharum STAB, São Paulo, v. 4 n. 14, p. 32-36, mai. 1981.

ZAMBELLO Jr.E.; HAAG H.P.; ORLANDO F.,J. Adubação NPK e Localização do Fertilizante em Soqueiras de Cana-de-açúcar, Variedade CB 41-76. Brasil Açucareiro, v.96, n.4, p.36-46. out.1980.

ZAMBELLO JR. E; Aplicação do sistema integrado de diagnose e recomendação para diferentes solos e épocas de amostragem foliar em soqueira de cana-de-açúcar (Saccharum, sp). Piracicaba, 1979. 95 p. Dissertação ( Mestrado ) - Escola Superior de Agricultura "Luiz de Queiróz", Universidade de São Paulo. 